\title{
Reexamining the Impact of Family Planning Programs on US Fertility: Evidence from the War on Poverty and the Early Years of Title $\mathbf{X}^{\dagger}$
}

\author{
Martha J. Bailey* \\ Martha J. Bailey: baileymj@umich.edu \\ *Department of Economics, University of Michigan, 611 Tappan Street, Ann Arbor, MI 48109
}

\section{Abstract}

Almost 50 years after domestic US family planning programs began, their effects on childbearing remain controversial. Using the county-level roll-out of these programs from 1964 to 1973, this paper reevaluates their shorter and longer term effects on US fertility rates. I find that the introduction of family planning is associated with significant and persistent reductions in fertility driven both by falling completed childbearing and childbearing delay. Although federally funded family planning accounted for a small portion of the post-baby boom US fertility decline, my estimates imply that they reduced childbearing among poor women by 19 to 30 percent. (JEL I38, $\mathrm{J} 12, \mathrm{~J} 13, \mathrm{~J} 18$ )

$[L]$ ess than five dollars invested in population control is worth a hundred dollars
invested in economic growth. —President Lyndon B. Johnson, 1965

It is my view that no American woman should be denied access to family planning assistance because of her economic condition. I believe, therefore that we should establish as a national goal the provision of adequate family planning services within the next five years to all those who want them but cannot afford them. This we have the capacity to do.

\section{- President Richard Nixon,1969}

The 1960s marked an important turning point in US population policy. Motivated by concerns over the international "population explosion" and the high fertility rates of the US baby boom, domestic family planning grants began under the 1964 Economic Opportunity Act, the centerpiece of President Johnson's War on Poverty, and continued under Title X of the 1970 Public Health Service Act, signed into law by President Nixon. The rationale for family planning programs was twofold. By subsidizing contraception, family planning programs would promote greater economic opportunities for disadvantaged women who "do not want more children than do families with higher incomes" but "do not have the information or the resources to plan their families effectively according to their own desires" (National Academy of Sciences 1963). In addition, the architects of the War on Poverty viewed reducing unwanted and ill-timed childbearing as a means to promote opportunities for children and, thus, achieve broader and longer term economic prosperity.

\footnotetext{
$\dagger$ To comment on this article in the online discussion forum, or to view additional materials, visit the article page at http://dx.doi.org/10.1257/app.4.2.62.
} 
More than 40 years later, the achievements of the US family planning program remain an open question. In fact, even the fertility effects of these programs are controversial. Although many economic models predict that family planning programs could reduce childbearing (Becker and Lewis 1973, Michael and Willis 1976), incorporating marriagemarket effects or moral hazard dimensions into these models (Akerlof, Yellen, and Katz 1996; Ananat et al. 2009) can lead to the counterintuitive prediction that family planning programs increase childbearing.

This theoretical ambiguity has not been resolved in the empirical literature. The conclusions of observational studies on family planning have been limited by well-known endogeneity problems (Rosenzweig and Wolpin 1986; Hotz, Klerman, and Willis 1997; Mellor 1998), and randomized trials have found limited (if any) evidence that family planning affects teen childbearing in the United States (Kirby 1997, DiCenso et al. 2002). Although the null results of these trials are inconclusive due to their short time horizons (which neglect longerterm effects), small sample sizes (which limit precision), and focus on teens (who may respond differently than nonteens), they provide little support for the view that family planning reduces births. ${ }^{1}$ Kearney and Levine's (2009) differences-in-differences study of changes in state-level Medicaid eligibility for family planning provides the best evidence to date that these programs reduce births for women near the poverty line for at least two years. But their identification strategy relies upon recent policy changes that affected the near poor, so it is unclear how their findings generalize to women with higher earnings and whether their shorter term effects persist in the longer term. This leaves open the question of how family planning programs have shaped family size, the intergenerational transmission of poverty, and longer term economic development.

This paper exploits the roll-out of federally funded family planning programs from 1964 to 1973 to evaluate both their shorter and longer term effects on child-bearing. The "wild sort of grant-making operation" (Gillette 1996, 193) during the period provides both a plausible, county-level identification strategy, and allows the effects of federally funded family planning to be evaluated over a 15 year horizon. Using a balanced panel of US counties from 1959 to 1988, I find that the introduction of family planning programs is associated with a significant and sustained reduction in childbearing. Ten years after these programs were established, the general fertility rate remained approximately 2 percent lower net of fertility reductions in similar communities that did not receive federal family planning dollars. This reduction was partially driven by a delay in childbearing, as teen births and births to women in their 20s remained lower. But the decline in the fertility rate also reflected a reduction in completed childbearing, evinced by sustained reductions in second and third births, lasting over a decade. Together, delayed childbearing and reductions in higher order births generated a decrease in the general fertility rate of 1.6 percent 10 to 15 years after these programs began.

Because federally funded family planning programs served mostly lower income women and operated in only one-fifth of all US counties, the program accounted for a small portion of the large decline in the general fertility rate from 1959 to 1974 . Nevertheless, the program had a profound effect on the women it served. The estimates imply that family planning programs reduced childbearing among poor women by 19 to 30 percent over a decade. This effect is as large as half to three-quarters of the 1965 fertility gap between poor and nonpoor women and suggests that federally funded family planning diminished the income-based differences in childbearing that motivated the program.

\footnotetext{
${ }^{1}$ Helmerhorst et al. (2006) note additional limitations of published randomized trials including intentional exclusion of participants after randomization, failure to use intention-to-treat analyses, and lack of treatment blinding.
} 


\section{A Brief History of US Family Planning Programs, 1964-1973}

Today, the most effective contraceptive methods are scientifically tested, US Food and Drug Administration approved, and medically prescribed. But historically, contraception was deemed obscene material and banned under federal and most state statutes (Tone 2001). After Enovid, the first birth control pill, was approved by the US Food and Drug Administration in 1960, a series of legal changes at the national and state level removed restrictions on the shipping, manufacturing, and sales of contraceptives to married and, later, unmarried women (Bailey et al. 2011).

Legal access, however, did not guarantee access in practice. Although "the Pill" was popular, it was prohibitively expensive. Shortly after its release, an annual supply of Enovid sold for the equivalent of about $\$ 760$ in 2010 dollars (Tone 2001, 257), roughly twice today's annual cost and amounting to more than three weeks of full-time work at the 1960 minimum wage. Both widespread concern about population growth (Wilmoth and Ball 1992, 1995) and studies showing that lower income women were having more children than they desired (National Academy of Sciences 1963) galvanized support for federal intervention.

The Early Expansion of US Family Planning Programs-Federal grants for family planning began under the Economic Opportunity Act (EOA 1964), the cornerstone legislation of President Johnson's War on Poverty. ${ }^{2}$ Although explicit language about family planning was not included in the EOA, the program fit within its funding authority. Sargent Shriver, the head of the Office of Economic Opportunity (OEO), began funding family planning programs through the Community Action Program (CAP) as early as 1964 (Levitan 1969).

Figure 1 shows gradual increases in federal outlays for family planning between 1965 and 1967 and two large increases in funding corresponding to two important policy changes. The first substantial increase in funding came with the 1967 amendments to the EOA, which designated family planning as a "national emphasis" program. From fiscal year 1967 to 1970, federal allocations to family planning increased by over 13 times their 1967 level to roughly $\$ 400$ million dollars (in 2010 dollars).

Like other CAP programs, any local organization could apply for family planning funding. ${ }^{3}$ Both the sensitivity of the family planning program (contraception was still a taboo topic and its sales were illegal in many states in 1964) and its small size resulted in few written records about funding decisions in the National Archives. Family planning funding comprised less than 0.4 percent of the 7.6 billion dollars in OEO outlays from 1965 to 1969 and less than 3 percent of the Community Action Program budget. While not about family planning specifically, Gillette's (1996) oral histories and interviews with former OEO officials provide a rich picture of the agency's functioning. OEO administrators report receiving applications for all of their programs from "various and sundry groups" often having little to do with the spirit of the legislation (Gillette 1996, 196 quoting Theodore M. Berry, assistant director of the OEO). Donald Baker, chief counsel of the OEO, recalls: "It was a wild sort of operation in those early days, making the first grants. We didn't have any guidelines and didn't have the time really to draft them to start out ... As a practical matter,

\footnotetext{
${ }^{2}$ According to 1967 estimates, expenditures for family planning through the Maternal and Child Health programs (started in 1942) and the Maternal and Infant Care programs under the 1963 Social Security Amendment were small (US Department of Health, Education, and Welfare (DHEW) 1974, 3).

${ }^{3}$ This feature of the CAP funding was intended to empower those who had been excluded from local politics to create positive changes in their community. It is also closely linked to civil rights. The direct-to-local-organization granting structure made the War on Poverty programs controversial, because they challenged traditional political structures and entrenched local interests.
} 
Sarge[nt Shriver, director of the OEO,] and [Jack] Conway[, head of the Community Action Program,] and many others in the Congress were pressing the program people to get the money out and to go, go, go and make the grants and make the contracts" (Gillette 1996, 193). Edgar Cahn, an attorney who worked closely with the OEO, described the agency's urgency "to move fast to shovel out the money, because a few precious, perfect projects won't do anybody any good" (Gillette 1996, 199).

The second large increase in funding for family planning occurred under the administration of President Richard Nixon. His 1969 Special Message to the Congress on the Problems of Population Growth advocated that they join forces to "establish as a national goal the provision of adequate family planning services within the next five years to all those who want them but cannot afford them." In November 1970, Congress responded by passing Title X of the Public Health Service Act (also known as the Family Planning Services and Population Research Act, P.L. 91-572). Importantly, Title X allowed the Department of Health, Education, and Welfare (DHEW) to make grants to local organizations directly and prohibited the use of federal funds "in programs where abortion is a method of family planning" (P.L. 91-572 § 1008). With Title X came important changes in family planning policies, priorities, and administrative responsibility as well as a good deal of confusion. At one point, for instance, DHEW's regional offices "refused to entertain local grant applications for family planning services, insisting instead that state health departments be the only vehicle for such applications" (Gould 1979), which reflected conflicts within the DHEW about how to implement Nixon's "new federalism" in order to shift control of funds from federal to state officials (Dryfoos 1976).

From 1969 to 1983, annual family planning service use increased by over four times (from 1.2 million to almost 5 million patients), in large part due to strong federal support and rising support from state and local governments. By 1973, federally supported family planning programs existed in over 650 US communities and served 1.9 million patients annually. By 1983, this number had grown to almost 5 million annually (Dryfoos 1988). Roughly 83 percent of family planning patients were below 150 percent of the poverty line (13 percent were AFDC recipients). Seventy percent of patients were white and roughly one quarter were black (284). Although the bulk of family planning funds was federal in the first decade of the program (Cutright and Jaffe 1977, 3), the Alan Guttmacher Institute (2000) estimated that, by 1980,50 percent of public support for family planning came from sources other than Title X. By 1994, 80 percent of public support came from sources other than Title $\mathrm{X}(13)$.

\section{Previous Research on US Family Planning Programs}

Almost 50 years since the first federally funded family planning programs began, the empirical evidence that they reduce birth rates is surprisingly thin. The earliest literature evaluating US programs provides mixed evidence of its effects on fertility (see Mellor 1998 for a review). ${ }^{4}$ Although these studies are closest to the period and programs considered in

\footnotetext{
${ }^{4}$ See Mellor's comprehensive, interdisciplinary literature review. For instance, Darney (1975) and Moore and Caldwell (1977) find that measures of family planning use and availability, respectively, are associated with reduced birth rates among black women. While Moore and Caldwell (1977) do not find a significant correlation between family planning use and fertility rates for white teens, Darney (1975) reports that the use of family planning increases birth rates among white women. On the other hand, Forrest, Hermalin, and Henshaw (1981) find no relationship between program enrollment in family planning programs and birth rates among black teens, but conclude that enrollment reduces birth rates among white teens. County-level studies of roughly the same period also come to contradictory conclusions. Udry, Bauman, and Morris (1976) find no significant relationship between average dollars spent per recipient of family planning services and births, whereas Cutright and Jaffe (1977) report that enrollment in family planning programs is associated with reductions in birth rates among blacks and whites. Weingarden (1974), Moore and Caldwell (1977), and Brann (1979) use cross-sectional comparisons at the state level. Darney (1975); Udry, Bauman, and Morris (1976); Cutright and Jaffe (1977); and Forrest, Hermalin, and Henshaw (1981) use cross-sectional comparisons of counties.
} 
this analysis, they are primarily cross-sectional and limited by well-known omitted variables and endogeneity problems (Rosenzweig and Wolpin 1986, Hotz, Klerman, and Willis 1997).

More recent studies using randomized trials of interventions to reduce teen pregnancies overcome these methodological limitations, but generally find that family planning programs had no effect on teen pregnancy in the United States. ${ }^{5}$ Indeed, DiCenso et al's. (2002) review and meta-analyses of 22 randomized studies of family planning, sex education, and abstinence interventions conducted from 1981 to 2000 conclude that these interventions did not increase the use of birth control among teens or reduce the number of teen pregnancies. Although these findings may not generalize to the broader US population, they are hardly an endorsement of family planning's fertility effects. Of course, the absence of program effects may reflect these trials' short horizons (treatment effects may take longer to manifest than the one to two years between baseline and follow-up) or small sample sizes (even pooled for meta-analysis). ${ }^{6}$

Quasi-experimental methodologies, ideal for addressing both endogeneity and power problems in the observational and experimental literatures, have been difficult to implement in the US context because federal funds for family planning have changed little since 1980 (Figure 1). Kearney and Levine's (2009) state-level, differences-in-differences study provides the most compelling and direct evidence to date that US family planning programs reduce birth rates. Using the state-by-year variation in Medicaid eligibility for family planning, they find that greater eligibility for family planning services in 17 states significantly reduced birth rates among teens (by 4 percent) and among older women (by 2 percent).

While suggestive, it is unclear how Kearney and Levine's results relate to the broader and longer-term effects of US family planning policy for several reasons. First, the effects of a global change in family planning policy considered in this paper may affect women in different income ranges (Kearney and Levine were able to examine effects for women whose incomes were 133 to 200 percent of the poverty line) or affect treated women differently. Second, the scale effects of family planning resources may be highly nonlinear. With diminishing returns to program scale (Schultz 1973, 1992), Kearney and Levine's (2009) marginal changes in program eligibility may understate the overall effects of early family planning programs on birth rates. Third, their shorter term effects may misstate the program's longer term effects. To the extent that changes in shorter term eligibility for family planning affect fertility due to better timing and increased birth intervals, Kearney and Levine's (2009) estimates may overstate the effects of family planning on completed fertility as well as on period fertility over a longer period. The ability to recover only shorter-term effects is not a limitation specific to Kearney and Levine's analysis. Schultz (2008) argues it is a general problem for studies of family planning. Although a handful of quasi-experimental studies in developing countries examine the longer term effects of family planning programs on childbearing, these studies do not easily generalize to the United States, where women's rights, knowledge, and resources may imply considerably different treatment effects (Joshi and Schultz 2007, Bangladesh; Salehi-Isfahani, Abbasi-Shavazi, and Hosseini-Chavoshi 2008, Iran; and Miller 2010, Colombia). ${ }^{7}$

\footnotetext{
${ }^{5}$ Ashraf, Field, and Lee (2010) find that the presence of a spouse when presenting wives with information about family planning has a substantial effect on their contraceptive use and unwanted childbearing in Zambia. The importance of spousal disagreement about the desired number of children may also play a role in the United States and affect the use of the Pill (because neither spousal knowledge nor consent is required to use it) as well as the use of free or reduced-cost family planning clinics (as they eliminate the need to bargain with a spouse over spending money on an expensive contraceptive).

${ }^{6}$ Helmerhorst et al. (2006) note additional limitations of published randomized control trials including intentional exclusion of participants after randomization, the failure to use intention-to-treat analysis, and the lack of treatment blinding.
} 
In summary, the shorter and longer term effects on US childbearing remain an open question. This reflects the difficulty of recovering causal effects with observational data or small-scale trials as well as the limited amount of variation in US family planning policies since the 1980s. This paper contributes to the literature by exploiting county-level variation in the roll-out of federally funded family planning programs between 1964 and 1973 to estimate the program's shorter and longer term effects on US childbearing.

\section{The Roll-Out of Family Planning Programs, 1964-1973}

Newly compiled information on family planning grants allows the analysis to document the establishment of federal programs in US communities from 1964 to 1973. The National Archives Community Action Program (NACAP) and National Archives Federal Outlay (NAFO) files provide two key pieces of information: (1) the county and state where services were delivered, which allows each program to be matched to the annual, county-level fertility statistics (the lowest level of geographic aggregation in the Vital Statistics records) and (2) the date of the first family planning grant, which provides a consistent proxy for when the program began operating. 8

Figure 2 describes the roll-out of federally funded family planning programs, showing their introduction by time period and by county of service provision. Note that in most cases, county or local governments were not grantees. County is used here because family planning programs are matched to counties in the Vital Statistics Natality Files. From 1965 to 1973, family planning programs began in each of the lower 48 states. Figure 2 categorizes counties receiving family planning programs (also called "funded counties") during these years into three periods: the initial programs established between 1964 and 1967; the programs established between 1968 and 1969, during the expansion of family planning as a national emphasis program; and programs established from 1970 to 1973, with the initiation of Title $\mathrm{X}$.

Immediately evident in Figure 2 is that funded counties were more urban, an impression confirmed by the 1960 census data presented in Table 1 . Counties receiving family planning programs had much larger populations. Roughly 60 percent of the US population of women ages 15-44 lived in the 654 funded counties in the estimation sample. (This is not surprising

\footnotetext{
${ }^{7}$ A closely related quasi-experimental literature examines the effects of changes in legal access to abortion and the birth control pill on birth rates during the 1960s and the 1970s (Levine et al. 1996; Guldi 2008; Bailey 2010). Using the staggered legalization of first trimester abortion in five states in 1970 and in the remainder with Roe $v$. Wade in 1973, Levine et al. (1996) show that birth rates fell more rapidly after 1970 in states with legal abortion. To examine the impact of the birth control pill on marital fertility, Bailey (2010) uses state-level variation in the language of Comstock statutes that banned the sales of contraceptives until 1965. Her analysis shows that fertility rates fell more rapidly in states without laws banning contraceptive sales. Guldi (2009) exploits state-level differences in the age of consent to show that the birth control pill reduced birth rates among younger, unmarried women as well. Although none of these studies consider the effects of greater financial access to family planning services on shorter and longer term birth rates, several consider the impact of changes in Medicaid income eligibility on abortions and births (Levine, Trainor, and Zimmerman 1996; Joyce, Kaestner, and Kwan 1998).

${ }^{8}$ The main limitation of the data is that they provide little documentation explaining the purpose of grants. To identify family planning awards, I used string searches on grant titles. In addition, fiscal year 1969 is missing from the electronic records. To minimize measurement error in the date of the first federal award and the location of service delivery, I compared the NACAP and NAFO data to printed, county-level OEO reports covering the universe of family planning programs in fiscal year 1968, calendar year 1969, and fiscal year 1971 (OEO 1969, 1971, 1974). This comparison allowed me to add the establishment of family planning programs in 278 communities. Only 23 of the remaining 378 dates were revised to reflect the earlier date in the OEO reports. Overall, the electronic records and printed reports agreed in 95 percent of cases where both are present. The analysis may miss some communities receiving their first grant before 1968. By necessity, these communities are grouped with unfunded communities. Under the assumption that these early, unobserved grants had similar effects to those I observe, this measurement error should lead the analysis to understate the effects of family planning programs. As an additional check on my data, the dates and grant amounts in my database are compared to Title X appropriations published by the Office of Population Affairs (OPA 2009). Because the OPA figures omit allocations through the Community Action Program, Figure 1 shows that my series, "Federal Outlays from All Sources," which includes both OEO and Title X grants, is larger than the OPA Title X series before 1974, when both Title X and the OEO funded family planning. The similarity of my data to the OPA figures after 1973, when the OEO was disbanded, suggests that my method captures the vast majority of federal family planning awards.
} 
given that urban areas have more organizations that could apply for funding and more infrastructure for programs to build upon.) Also consistent with family planning programs being in more urban areas, funded counties had fewer elderly residents and had more of their population above the 1960 poverty line for a family of four $(\$ 3,000)$. They were also more educated and affluent. Importantly, counties with federal programs did not have higher fertility rates (as proxied by the proportion of the 1960s population under five years of age) or more nonwhite residents. ${ }^{9}$ These observed differences and their suggestion of unobserved differences motivate the inclusion of county fixed effects in the analysis. Therefore, timeinvariant cross-sectional differences in county characteristics are not a threat to the internal validity of this study (as in many cross-sectional studies), but they are important to keep in mind when considering the study's external validity.

Figure 2 also describes the significant within-state variation in the establishment of federally funded family planning programs. For instance, the first US community to receive a family planning program was Corpus Christi, Texas in 1964, but Ector and Gonzales, Texas did not receive a program until 1973. In 43 of the lower 48 states, programs were established in at least two different years. Counties in 41 states established family planning programs in at least four different years. In more than half of states, programs were established in at least five different years. This within-state variation is useful for this analysis as it allows the inclusion of state-by-year fixed effects, which absorb time-varying changes in state policy like abortion legalization, Medicaid expansion, and changes in laws governing the age of access to contraception.

Key to this paper's identification strategy is that when family planning programs were established is as good as random after conditioning on other model covariates. Before proceeding to the main analysis, I examine this assumption by providing evidence that federal grant making was as disorganized as the oral history suggests. As a starting point, I test whether 1960 county characteristics predict when a federal family planning program began. Although family planning programs were established earlier in areas with greater urban populations, the analysis shows little evidence that other 1960 county characteristics were used to prioritize funding. After flexibly accounting for the share of a county population in urban areas and state fixed effects, none of the 1960 population characteristics consistently predicts when counties received their programs. ${ }^{10}$ Notably, differences in lagged fertility measures (share of the population under age five) and poverty rates do not predict establishment dates in any specification, despite the stated objective of the program to help reduce poverty.

Another possibility is that establishment dates may be correlated with more current fertility levels or recent fertility changes. If proposals were more likely to originate in or be funded in locations with high fertility rates, then the event study may pick up reversion to the mean or the later end of the baby boom. Alternatively, OEO officials, eager to claim results for the program, may have used observed changes in fertility rates to prioritize proposals, and given higher priority to locations where fertility rates were already falling or falling faster. Figure 3 , however, provides no evidence of the systematic application of or funding priority for organizations on the basis of observable fertility rates.

\footnotetext{
${ }^{9}$ The latter is inconsistent with claims that federally funded family planning programs were motivated by racism at the OEO. ${ }^{10}$ I regress the date federally funded family planning programs were established on 1960 county characteristics. These regressions include characteristics in Table 1, except population size because it is highly collinear with proportion of residents in urban areas. I also include state fixed effects and, therefore, omit regional dummies. The proportion of residents above age 64 significantly predicts receiving a family planning program sooner in weighted regressions but not in unweighted regressions. The failure of these characteristics to predict the timing of adoption differs from results in Hoynes and Schanzenbach (2009), who report statistically significant relationships between many of these characteristics and the initiation of food stamps programs. Of course, my analysis has less detail than theirs in dates (they use month-year dates) and fewer treated counties (every US county received a food stamps program in their analysis). Regression coefficients are available upon request.
} 
Yet another hypothesis is that federal family planning establishment reflected local attitudes about contraception and childbearing, which were not correlated with the 1960 census characteristics or fertility outcomes. If, for instance, proposals originated sooner in locations with more permissive views about contraception and sex out-of-wedlock childbearing (even though they had similar childbearing outcomes) and these views predicted future fertility declines, then the roll-out of family planning programs could be spuriously correlated with future changes in fertility. The 1965 National Fertility Study (NFS), designed to illuminate the determinants of childbearing among ever-married women, allows a direct test of this hypothesis. Yet, Table 2 shows little relationship between the date of establishment and 16 measures of attitudes and outcomes related to contraception and childbearing. ${ }^{11}$ These outcomes include attitudes about the dangers of world population growth, abortion, and the ideal number of children, as well as coital frequency in the last four weeks, the use of the birth control pill, and whether the respondent or her spouse had operations "making it impossible to have another child." The date of program establishment is also uncorrelated with women's education, Catholicism, age at first marriage and remarriage, age at first pregnancy, the total children born, and husband's income in 1965. It is also uncorrelated with childhood characteristics, such as whether the respondent lived with both parents at age 14 and the number of the respondent's mother's children.

In summary, this quantitative evidence is consistent with the idea that federal grantmaking and the timing of local applications reflected a variety of idiosyncratic factors. Neither 1960 census characteristics, 1964 fertility levels, 1960-1964 fertility changes, nor a rich set of 1965 measures of sexual behavior, birth control use, and childbearing predict when federal family planning programs began during the 1964 to 1973 period. However, the event-study results show that the date a family planning program began systematically predicts when fertility rates began their more rapid decline in over 600 funded communities. The next section describes changes in fertility over the 1960s and 1970s, introduces the event-study regression framework, and examines the framework's identifying assumptions.

\section{Empirical Strategy: Event-Study Analysis}

Data on family planning programs are linked to birth records from Vital Statistics from 1959 to 1988 . The main outcome of interest, the general fertility rate (GFR), is defined as the number of births by county of mother's residence per 1,000 women of childbearing age (15 to 44 years). Although county-level birth rates by age group and parity are not available before 1968, I use county-of-residence aggregates using NHCS microdata for 1968-1988 to create age- and parity-specific birth rates. ${ }^{12}$

Panel A of Figure 4 shows changes in the GFR of the estimation sample of counties with family planning programs established in three periods and for unfunded counties. For instance, counties in the "First funded 1965-1967" group had programs established between 1965 and 1967. The "Unfunded" group had not received a federal family planning program by 1973 and corresponds to unshaded counties in Figure 2 and to column 2 of Table 1. For each group, the GFR evolves nonlinearly over the 1959-1988 period, as the baby boom ends. Panel B plots the raw difference in the GFR between the funded counties and unfunded counties. From 1959 to 1965, the relatively flat lines for each of the series in panel

\footnotetext{
${ }^{11}$ I regress each characteristic on the date a federally funded family planning program was established in the respondent's county of residence. To account for the stratified sample design of the 1965 NFS, I include dummy variables for the size of the sampling unit, decade of birth, and race.

${ }^{12}$ The numerator for the 1959-1968 GFR was hand entered from published Natality Volumes; the numerator for the 1968-1988 GFR was aggregated from NCHS microdata to mother's county of residence. Denominators for all birth rates were constructed for 19591968 by linearly interpolating information between the 1950, 1960, and 1970 censuses (Haines 2005); GFR denominators for the 1969-1988 period use the Surveillance Epidemiology and End Results (SEER) data.
} 
B indicate that, before family planning programs began, the difference in the GFRs in funded and unfunded locations did not change- that is, fertility rates declined similarly in locations eventually getting programs and locations that did not. Simply subtracting the GFR in unfunded counties completely accounts for the nonlinear evolution of the GFR from 1959 to 1974 , including the fertility notch of the late 1960 s and the dramatic post- 1970 fall in fertility. After 1966, however, the GFR in funded counties diverges systematically by the date that the family planning program began operating. After 1967, the GFR fell more rapidly in counties receiving family planning programs between 1965 and 1967 than in unfunded locations. Similarly, after 1969, the GFR fell more rapidly in counties receiving family planning programs between 1968 and 1969 than in unfunded locations. Finally, after 1973, the GFR fell more rapidly in counties receiving family planning programs between 1970 and 1973 than in unfunded locations. Also consistent with family planning having a treatment effect, the GFR in counties funded from 1965 to 1967 fell before the GFR in counties first receiving a program from 1968 to 1969, and so forth. In short, both comparisons of funded to unfunded locations and comparisons by date of establishment among funded locations suggest that family planning programs reduced fertility.

\section{A. Event-Study Regression Framework}

An event-study specification (Jacobson, LaLonde, and Sullivan 1993) formalizes this analysis by mapping the exact year of fertility declines to my proxy for the fiscal year when family planning programs began. It also permits the inclusion of a rich set of fixed effects and time-varying covariates to adjust Figure 4's differences for potentially confounding factors. I estimate the following linear model,

$$
Y_{j, t}=\theta_{j}+\gamma_{s(j), t}+\sum_{y=-7}^{-1} \pi_{y} D_{j} 1\left(t-T_{j}^{*}=y\right)+\sum_{y=1}^{16} \tau_{y} D_{j} 1\left(t-T_{j}^{*}=y\right)+X_{j j}^{\prime} \boldsymbol{\beta}+\varepsilon_{j, t},
$$

where $Y_{j, t}$ is a fertility outcome in county $j$ in year $t=1959, \ldots, 1988$ (for age group and parity estimates, $t=1968, \ldots, 1988) ; \theta_{j}$ is a set of county fixed effects; $\gamma_{s(j), t}$ is either a set of year fixed effects or state-by-year fixed effects, which capture time-varying, state-level changes in abortion legalization, changes in Medicaid policy, and changes in family planning funds in Title V of the 1967 Amendment to the Social Security Act; ${ }^{13}$ and $X_{j t}$ is a column vector including a constant and a set of covariates that exhaust the information available to OEO administrators. These covariates include annual and county-level, per capita measures of government transfers using data from the Bureau of Economic Analysis Regional Information System (REIS) (cash public assistance benefits, such as Aid to Families with Dependent Children, Supplemental Security Income, and General Assistance; medical spending, such as Medicare and military health care; and cash retirement and disability payments) and one of the following: the interaction of 1960 census characteristics in Table 1 (share of population in urban area, nonwhite, under age 5, over 64 years of age; share of households with income under $\$ 3,000$, over $\$ 10,000$, and the share of the county's land that is rural or a farm) with linear time trends, or county-specific linear trends. In addition, information on the number of abortion providers in each county accounts for within-state changes in the availability of abortion from 1970 to 1988 (zero before 1970). ${ }^{14}$ Federal funds for family planning did not go to programs providing abortion, so the

\footnotetext{
${ }^{13}$ In 1967, Title V of the Social Security Act mandated that at least 6 percent of funds for child and maternal health at the state level be earmarked for family planning services (P.L. 90-248, Title V, §§502, 505a, 508a; Title IV, §201a).

${ }^{14}$ The first two sets of county characteristics in $X$ are similar to specifications in Almond, Hoynes, and Schanzenbach $(2008,15)$. The REIS data were generously provided by Almond, Hoynes, and Schanzenbach. The third set was generously provided by the Alan Guttmacher Institute and Ted Joyce. Note that changes in the distance to states providing legal abortion before 1973 are accounted for in the state-by-year fixed effects.
} 
estimated effects of family planning should reflect sex education, counseling (and possible referral for abortion), and the provision of contraceptive supplies.

Of interest are the coefficients on the interaction of $D_{j}$, a dummy variable equal to one if the county ever received a family planning grant, and an indicator function, 1(), which is equal to one when the year of observation is $y=-7,-6, \ldots, 15,16$, years from the date, $T_{i}^{*}$, the year that a federally funded family planning program was established in county $j .{ }^{15}$ Because the indicator for $y=0$ is omitted, the set of $\pi$ describes the differential evolution of outcomes in funded counties before the family planning program began. The set of $\tau$ describes the evolution of outcomes $y$ years after the family planning program began. Key to isolating the federal shock to the supply of family planning services is the inclusion of county effects, which allows consistent estimation of $\pi$ and $\tau$ even in the presence of timeinvariant, unobserved differences between funded and unfunded locations.

One advantage of this specification is that it relaxes the standard differences-indifferences (DiD) assumption that treatment is associated with a one-time, level shift in outcomes. A family planning program cannot be set up instantaneously, implying that the initial program effects may be smaller due to a smaller clientele or construction of facilities. Moreover, if family planning programs allow women to delay childbearing by several years, then a fully functional facility could initially depress birth rates but raise them later. The flexible specification in (1) allows the analysis to characterize changes in the program effect over 15 years and sheds light on how much of the effect found by Kearney and Levine reflects shorter term adjustments in birth timing versus longer-term changes in completed fertility. Another advantage of this specification is that the $\pi$ 's provide a visual and statistical depiction of differential, preexisting trends that may confound estimates of $\tau$. They also show whether the "treatment effects" preceded the program even by a few years-an important falsification test.

After presenting the event-study results, the main results are summarized in a DiD specification, in which the individual indicators in equation (1) are replaced with dummies for 5 -year categories for the periods -6 and before, -5 to $-1,1-5,6-10,11-15$, and 16 or more years after the establishment of a federal family planning program. Although all lead and lag dummies are included in all specifications, figures and tables only present estimates for event-years that are based upon a balanced set of counties (years -6 to +15 for the event study, -5 to +15 for the $\mathrm{DiD})$.

\section{B. Testing for Threats to Internal Validity}

Potential threats to the internal validity of the analysis are shocks that are correlated with fertility rates, concentrated in funded counties, and coincident to or occurring just after the family planning program began. One potential confounder is coincident local initiatives. However, it seems unlikely that "various and sundry" organizations in over 600 counties would begin initiatives to reduce fertility that happened to coincide with the initiation of a federal family planning program. (If a complementary community family planning initiative begins because of the increase in federal family planning funds, the event-study would appropriately incorporate these indirect, "crowd-in" effects.) And, even if applicants for federal funding also began local programs, application rejections and administrative delays make it unlikely that federal grants would be funded at the same time as local programs started.

\footnotetext{
${ }^{15}$ To ensure the model parameters are well estimated, values of $y \leq-7$ are grouped with -7 , and all values greater than 15 are grouped into the category 16.
} 
The more plausible threat to identification is the coincidence of other federal spending. Although the oral histories provide little indication that OEO administrators deliberately packaged OEO programs, this may have happened inadvertently or because certain communities were more effective at writing proposals. This is an important concern, because other War on Poverty programs also impacted fertility and health. For instance, Ludwig and Miller (2007) show that Head Start programs reduced child mortality, while Almond, Hoynes, and Schanzenbach (2008) report that food stamps programs increased birth weight and decreased neonatal infant mortality. Other programs like community health centers or maternal and infant health projects often provided services for family planning and aimed to improve infant and maternal health (DHEW 1974, 5; Dryfoos 1988). If the establishment of family planning programs coincided with the start-up of other federal programs, then estimates of $\tau$ may fail to isolate the effects of the family planning program.

Using newly compiled information on all grants for other OEO programs, I test this by estimating equation (1) with a dependent variable for grant receipt $(=1)$ for each of eight OEO programs as the dependent variable. ${ }^{16}$ Event-study estimates presented in Figure 5 are relative to the year the county received its federal family planning program. Panel A of Figure 5 is presented to fix ideas; counties receiving family planning programs got their first grant at time zero. There is no pre-trend, and subsequent coverage rates indicate that federal refunding occurred in many but not all cases. ${ }^{17}$ In contrast, panels B to E show little evidence of an abrupt shift in funding for other programs in the year the family planning program was established. Funding for community health centers (panel B), Head Start (panel C), jobs programs (panel D), and legal services (panel E) show very small or no increases predating the establishment of family planning programs, and funding did not differentially increase in funded counties over the years when family planning funding expanded. The next two panels of Figure 5 examine the coincidence of first family planning grants with maternal and infant care projects (panel F) and maternity and infant health projects (panel G). These plots do not support the view that other program funding experienced trend breaks in the year of the first family planning grant. This is not an exhaustive list of programs, but this evidence does alleviate concerns of packaged federal spending on six of the more likely, potentially confounding, federal programs.

In summary, much evidence supports the internal validity of this study's research strategy. Descriptive findings show program establishment dates are not predicted by 1960 census characteristics nor 1964 fertility levels, 1960-1964 fertility nor 1965 measures of sexual behavior, birth control use, and childbearing. This section further narrows the scope for omitted variables bias by showing that expansions in other federal program funding do not coincide with the roll-out of family planning. Consequently, the next section treats the establishment of federal family planning programs as exogenous shocks to the supply of these services and examines their impact on childbearing.

\section{Results: Did Family Planning Programs Reduce US Fertility Rates?}

Using equation (1), Figure 6 presents event-study estimates of the effects of federal family planning programs on the GFR, and Table 3 summarizes the magnitudes and their joint significance in five-year groups. Specifications in panel A of Table 3 weight the results by the 1970 population of women ages 15 to 44 and, therefore, represent the effects for the average woman of childbearing age in that year. Figure 6 shows three specifications: model

\footnotetext{
${ }^{16}$ Because grant information for other federal programs are missing in 1969, I omit this year from the sample (failing to do so would favor finding no correlation in timing between a first family planning grant and other programs). Moreover, I only use counties for which I observe first grants in the OEO data.

${ }^{17}$ This is not an indication that these programs were discontinued because state and local funds for these programs were increasing over the same period (AGI 2000). Funds from nonprofit sources were also increasing.
} 
1 includes county and year effects (assumes $\gamma_{s(j), t}=\gamma_{t}$ ); model 2 adds state-by-year fixed effects to model 1; and model 3 adds the time-varying, county-level covariates to model 2. Table 3 also shows that the addition of linear, county trends (column 4) yields slightly larger estimates, although they are statistically indistinguishable from those in column 3.

Across models, the results show that the establishment of federal family planning programs reduced childbearing. In all models, the GFR evolved similarly in funded and unfunded counties before family planning programs began. Pretreatment, covariate-adjusted differences between funded and unfunded counties are close to zero and individually statistically insignificant. Table 3 also shows that the average leads for years -5 to -1 are also indistinguishable from zero in each model. After family planning programs began operating, however, all models show a trend break. In the first five years of program operation, the GFR fell more quickly in funded counties than in unfunded counties. Within three years of the program establishment, the GFR had fallen by over 1 birth per 1,000 women of childbearing age (Figure 6 model 3, panel A) and almost 2 births per 1,000 women in the average county (Figure 6 model 3, panel B). By years 6-10, the GFR had fallen by an average of 1.5 (Table 3A model 3) and to 2.1 (Table 3B model 3) births per 1,000 women of childbearing age. The growth in the effects is consistent with the earliest federal grants establishing or significantly expanding family planning programs and with these programs reaching their full capacity in 4 to 5 years. After the initial 5 -year period, the GFR changed similarly in funded and unfunded counties, so the difference changed little over the next decade. Ten years after family planning programs began, the GFR remained roughly 1.4 to 2 percent lower than in the year the program started, net of the declines captured by the econometric model.

Two specification checks underscore the robustness of these findings. Under the assumption that funded counties evolved differently than unfunded counties (an assumption at odds with the absence of a pre-trend in Figure 6), one might include only funded counties in the regressions. Using funded counties only, column 5 of Table 3 shows evidence of a trend break in the year after the grant, but omitting the unfunded counties results in less precise estimates. In neither the weighted nor the unweighted specifications are these estimates statistically distinguishable from those in models containing unfunded counties as well. The exclusion of unfunded counties, therefore, does not change the patterns of results. A second check considers the difference in the effects for pre-Title $\mathrm{X}$ and post-Title $\mathrm{X}$ family planning programs. Although the magnitudes differ modestly, grants in both periods reduced the GFR by 1.9 to 2.3 percent in years 6 to 10 (columns 6 and 7, Table 3A). The event studies (omitted for brevity) also show that, for grants in both periods, the estimates exhibit a trend break in the year after the family planning program began.

Taken together, these results provide robust evidence that federal family planning programs reduced childbearing. Given the extensive controls included in the analysis, it is encouraging that the pattern of estimates varies so little across specifications. Interestingly, the trend break and the absolute magnitude of the effects tend to be larger in unweighted specifications, which implies that the effects were stronger in less populous counties. This may reflect differences in the share of a county's women who were affected (treated women may have been a larger proportion of the population in smaller counties) or heterogeneity in the effect across locations (larger cities may have had more nonprofit/private alternatives to federal family planning).

The reductions in the GFR may reflect both changes in the timing of childbirth as well as reductions in completed fertility. I examine these channels by considering age-specific birth rates as well as birth rates by parity, which I construct using the natality microdata from 1968 to 1988 (these regressions omit counties funded before 1968 from the analysis to 
ensure a balanced panel of treated counties in the post-period). ${ }^{18}$ Fertility delay is not observed directly, but delayed childbearing is evident in large reductions in fertility among younger women, whereas reductions in completed fertility manifest as reductions in higher parity births. Figure 7 and Table 4 present event-study estimates consistent with both channels. Panel A of Figure 7 and Table 4 show that, following the establishment of a federally funded family planning program, birth rates for women 15 to 39 years of age tended to decrease. Six to ten years after the program began, the largest absolute drop in levels was approximately 3 births per 1,000 women, or 2.2 percent, among 25-29-year-olds (Table 4, column 3 ). The reduction among teens reached approximately 2.3 percent (column 1 ), while the effects for women in their early 20 s and early 30 s were around 1.3 percent (columns 2 and 4). Changes in birth rates among women in their late 30s are negative, but they are statistically insignificant. Consistent with reductions in completed childbearing, panel B of Figure 7 and Table 4 show that the introduction of a family planning program also reduced the number of first, second, and third births by 2.1, 2.7, and 1.8 percent, respectively, 6 to 10 years after the family planning program started, as well as in the longer term (years 11 to 15). The roughly 20 to 30 percent reduction of the magnitude of these effects in the last 5 -year period, however, is consistent with family planning programs helping women to delay higher order births. Estimates for fourth and fifth births are also negative, but imprecise. Together, these results imply that family planning programs induced childbearing delay for 15 to 34 -year olds and achieved a significant reduction in completed fertility as well.

\section{How Large Are the Effects of Federal Family Planning Programs?}

Thus far, the paper has examined changes in fertility rates following the establishment of federal family planning programs and builds a case for family planning programs themselves reducing fertility. Given the robustness of the estimates across models, this final section examines the plausibility of the estimated magnitudes from two different perspectives. First, I use a back-of-the-envelope calculation to examine whether the estimated effects of family planning programs make sense given my approximation of their effects on contraceptive failure rates. Second, I approximate the treatment effect of family planning programs on women who used them (average treatment effect on the treated, ATET), and compare this effect to fertility rate differences by income in 1965 .

\section{A. Back-of-the-Envelope Calculation of the Expected Effects of Family Planning on Fertility}

Family planning programs may both increase the share of women choosing to prevent pregnancies at a given time (by decreasing the marginal cost of using contraception) and reduce the likelihood of contraceptive failure among contraceptive users (by subsidizing more reliable methods like the Pill). This back-of-the-envelope calculation approximates the impact of family planning on births through the failure channel only and assumes that federal family planning programs have no effect on the choice to get pregnant or sterility rates.

My approach follows Bailey (2010) and requires an estimate of the national failure rate before family planning services began, which I derive from the following tautology. The GFR in year $t$ can be written as the sum of the planned birth rate, $P_{t}$, and the unplanned birth rate due to contraceptive failures, $F_{t}$, or $G F R_{t}=F_{t}+P_{t}$ Planned births and failures reflect decisions in the previous period about whether or not to get pregnant as well as the respective success and failure rates of these endeavors. If $Q$ denotes the share of women

\footnotetext{
18 Parity measures (panel B) are the number of births of the indicated parity divided by the population of women ages 15-44. Panels A of Figure 6 and column 8 of Table 3 show that the aggregate estimates for this shorter panel are similar in magnitude to the estimates for the longer panel.
} 
who are fecund and trying to get pregnant, $S$ the share of women who are not fecund, $s$ the time-invariant average rate of success among women trying to get pregnant, and $f$ the average failure rate among fecund women, then the GFR can be written as

$$
G F R_{t}=F_{t}+P_{t}=Q_{t-1} s+\left(1-Q_{t-1}-S_{t-1}\right) f .
$$

In 1966, the US marital GFR was 131 per 1,000 married women ages 15 to 44. (I compute the marital GFR because the 1965 NFS only contains information on ever-married women.) The 1965 NFS indicates that $Q$ and $S$ are 0.023 and 0.26, respectively. Trussell (2004) places the likelihood of pregnancy occurring within a year among women who are trying at 0.85 . For the US marital fertility rate to have reached 131 per 1,000 married women in 1966, these numbers imply that, before the US family planning program began, roughly 15.5 percent $(f=(0.131-0.023 \times 0.85) /(1-0.023-0.26)=0.155)$ of married US women who were not trying to get pregnant in 1965 conceived children. (This national failure rate is much lower than the rate implied by an estimate of individual method failures weighted by use.)

Using this pre-federal family planning program failure rate, I compute a DiD estimate of how family planning affected the $G F R$ by rewriting equation (2) as $G F R_{t}=Q_{t-1} s+(1-$ $\left.Q_{t-1}-S_{t-1}\right)\left[\theta_{t-1} f^{F}+\left(1-\theta_{t-1}\right) f\right]$, where $\theta_{t-1}$ denotes the share of the fecund women using family planning services, and $F^{F}$ the average failure rate for family planning program users. The change in the difference in birth rates between communities receiving family planning programs, $G F R_{t}^{F}$, and unfunded communities, $G F R_{t}^{U}$, between period $T$ and the date of the family planning program's establishment, 0 , can be written,

$\Delta D \equiv\left(G F R_{T}^{F}-G F R_{T}^{U}\right)-\left(G F R_{0}^{F}-G F R_{0}^{U}\right)$. Assuming no initial differences in $Q$ and $S$ and that the federal family planning family program did not change $Q$ and $S$, or $\left(1-Q_{0}^{F}-S_{0}^{F}\right)=\left(1-Q_{0}^{U}-S_{0}^{U}\right)=\left(1-Q_{T}^{F}-S_{T}^{F}\right)=\left(1-Q_{T}^{U}-S_{T}^{U}\right)$, the DiD estimate of family planning simplifies to depend upon three quantities: the share of women who are fecund and not trying to get pregnant, the difference in the share of women using family planning services in funded and unfunded locations, and the difference in failure rates conferred by family planning programs, or

$$
\Delta D=\left(1-Q_{T}-S_{T}\right)\left(\theta_{T}^{F}-\theta_{T}^{U}\right)\left(f^{F}-f\right) .
$$

The 1965 NFS implies that $\left(1-Q_{T}-S_{T}\right)=0.717$. Assuming that the failure rates of services supplied by family planning programs (i.e., the Pill) are around those implied by "typical use" ( 2 to 8 percent), $\left(f^{F}-f\right)$ ranges from -0.075 to -0.135 . I estimate the final unknown, $\left(\theta_{T}^{F}-\theta_{T}^{U}\right)$, using the $1970 \mathrm{NFS}$, which asked ever-married women between the ages of 18 and 44 whether they had ever used the Pill, the most prescribed method by family planning clinics. Using a probit specification, I find that federal family planning programs raised cumulative use of the Pill by 5 percentage points. ${ }^{19}$ Altogether, this simple approximation implies a DiD estimate, $\Delta D$, that ranges from $-2.7(0.717 \times 0.05 \times-0.075)$ to $-4.8(0.717 \times 0.05 \times-0.135)$ births per 1,000 married women. Given that this approximation could be even larger if federal family planning programs affected the share of

\footnotetext{
${ }^{19}$ The dependent variable is 1 if the respondent "ever used the Pill." The sample includes only PSUs in counties that received a family planning program from 1964 to 1973 . The regression includes binary indicators for size of PSU and a binary variable equal to one if a woman's PSU was in a county with a federal family planning program before the 1970 survey. The marginal effect of having a federal family planning program at the mean implies a 0.050 percentage point increase in Pill use (standard error 0.028 ).
} 
women trying to get pregnant, my estimates ranging from -1.2 to -1.9 births per 1,000 women (Table 3A, years 6-10) are plausible. ${ }^{20}$

\section{B. Treatment Effects on the Treated: Family Planning's Effects on New Users}

Because not all residents of a county would have increased their use of family planning with the introduction of a federally funded program (many women would have obtained services in its absence from other providers), Section V's intention-to-treat (ITT) effects understate the effects of family planning on the women they served ("treated women"). To approximate the effects of federal family planning programs on treated women (ATET), I rescale these ITT effects by the induced changes in use of the Pill. I use changes in the use of the Pill rather than changes in family planning services use, because this measure has the advantage of capturing substitution toward more reliable methods, which tend to reduce fertility rates by reducing contraceptive failures. Because the 1970 NFS estimate that federal family planning programs increased use of the Pill by 5 percentage points, a reduction in the period birth rate between 1.2 and 1.9 (Table 3A, years 6-10) implies a ATET of $-24(-1.2 / 0.05)$ to $-38(-1.9 / 0.05)$ births per 1,000 women.

Is such a reduction among treated women reasonable? Because women below 150 percent of the poverty line were the majority of service users (and Vital Statistics natality data do not contain information on income), I use the 1964-1966 Natality Followback Survey (US DHHS ICPR 2008) to generate a pre-program estimate of differences in childbearing by income. This survey shows that the GFR among women below 150 percent of the poverty line was 128 , but that the GFR among women above that threshold was 77 . The approximated ATET, therefore, implies a 19 (24/128) to $30(38 / 128)$ percent reduction in childbearing for women below 150 percent of the poverty line and is as large as $47(24 / 51)$ to $75(38 / 51)$ percent of the fertility gap between poor and nonpoor women before the program began. In short, the effects are large but reasonable. They are also consistent with federally funded family planning programs diminishing the income-based differences in childbearing that motivated the program.

\section{Reevaluating the Fertility Effects of Family Planning}

For almost 50 years the federal government has invested in domestic family planning programs with mixed evidence of their short-run effectiveness and limited (if any) evidence that these programs reduced US childbearing in the longer term. The impact of these programs on childbearing in the United States was contentious in the 1960s and it remains so today. ${ }^{21}$ Although recent research has argued that the birth control pill played an important role in reducing US fertility rates (Guldi 2008; Bailey 2010), these studies' reliance on legal variation only provides evidence on the importance of modern contraception for women who could afford it.

This paper adds to the literature by considering how family planning programs' subsidization of contraception affected childbearing in both the shorter and longer run. Using county-level variation when family planning programs were established between 1964 and 1973, I find that domestic family planning programs had a sustained impact on childbearing by ameliorating income-based differences in access to more reliable contraceptives. My estimates imply that US family planning programs prevented roughly 1.8

\footnotetext{
${ }^{20}$ Although I have no way to evaluate this directly (the $N F S$ did not sample never-married women), the effect may be larger or smaller depending upon how family planning affected this group.

${ }^{21}$ See, for example, the heated exchange in Science featuring the provocative articles, "Population Policy for Americans: Is the Government Being Misled?" (Blake 1969) and "Family Planning and Public Policy: Who is Misleading Whom?" (Harkavy, Jaffe, and Wishik 1969).
} 
million births in the first 10 years they existed at a cost of roughly $\$ 2,700$ federal dollars per birth averted. ${ }^{22}$

Because federally funded family planning programs served mostly lower income women and operated in only one-fifth of all US counties in 1974, the program accounts for a modest portion of the large decline in the general fertility rate from 1959 to 1974. Nevertheless, these programs had a substantial effect on the women they served. This paper's estimates imply that federal family planning dollars reduced childbearing among poor women by 19 to 30 percent within 10 years-magnitudes large enough to account for half to three-quarters of the 1965 gap in childbearing between poor and nonpoor women. Future work should consider how family planning programs affected a host of longer term outcomes including the age structure of poverty, children's resources and life chances, and economic growth.

\section{References}

Akerlof, George A.; Yellen, Janet L.; Katz, Michael L. An Analysis of Out-of-Wedlock Childbearing in the United States. Quarterly Journal of Economics. 1996; 111(2):277-317.

Alan Guttmacher Institute (AGI). AGI Report. New York: 2000. Fulfilling the Promise: Public Policy and U.S. Family Planning Clinics.

Almond, Douglas, Hilary W. Hoynes, and Diane Whitmore Schanzenbach. . National Bureau of Economic Research Working Paper. 2008. Inside the War on Poverty: The Impact of Food Stamps on Birth Outcomes; p. 14306

Ananat, Elizabeth Oltmans; Gruber, Jonathan; Levine, Phillip B.; Staiger, Douglas. Abortion and Selection. Review of Economics and Statistics. 2009; 91(1):124-36.

Ashraf, Nava; Field, Erica; Lee, Jean. Household Bargaining and Excess Fertility: An Experimental Study in Zambia. 2010. http://www.economics.harvard.edu/faculty/field/files/Ashraf_Field_Lee_November2010.pdf

Bailey, Martha J. 'Momma's Got the Pill': How Anthony Comstock and Griswold v. Connecti-cut Shaped US Childbearing. American Economic Review. 2010; 100(1):98-129.

Bailey, Martha J. Reexamining the Impact of Family Planning Programs on US Fertility: Evidence from the War on Poverty and the Early Years of Title X: Dataset. American Economic Journal: Applied Economics. 2012. http://dx.doi.org/10.1257/app.4.2.62

Bailey, Martha J.; Guldi, Melanie; Davido, Allison; Buzuvis, Erin. Early Legal Access: Laws and Policies Governing Contraceptive Access, 1960-1980. 2011.

www-personal.umich.edu/ baileymj/ELA_laws.pdf

Becker, Gary S.; Gregg Lewis, H. On the Interaction between the Quantity and Quality of Children. Journal of Political Economy. 1973; 81(2):S279-88.

Blake, Judith. Population Policy for Americans: Is the Government Being Misled? Science. 1969; 164(3879):522-29. [PubMed: 4888103]

Brann, Edward A. A Multivariate Analysis of Interstate Variation in Fertility of Teenage Girls. American Journal of Public Health. 1979; 69(7):661-66. [PubMed: 453392]

Cutright, Phillips; Jaffe, Frederick S. Impact of Family Planning Programs on Fertility: The US Experience. New York: Praeger; 1977.

Darney, Philip D. Fertility Decline and Participation in Georgia's Family Planning Program: Temporal and Areal Associations. Studies in Family Planning. 1975; 6(6):156-65. [PubMed: 1154482]

Alba, DiCenso; Guyatt, Gordon; Willan, A.; Griffith, L. Interventions to Reduce Unintended Pregnancies among Adolescents: Systematic Review of Randomised Controlled Trials. British Medical Journal. 2002; 324:1426-33. [PubMed: 12065267]

\footnotetext{
${ }^{22}$ Births averted estimates are obtained by multiplying the mean population of women ages 15 to 44 in funded counties in 1970 (145, 193) by the event-study estimates for model 3 and summing over years 1 to 10 . Federal outlays from 1965 to 1980 for family planning are estimated at $\$ 5,067$ million (2010 dollars). Thus, the reduction in births cost roughly $\$ 2,734$ in federal dollars per birth averted in the program's first 10 years. Due to the large (unknown) contributions from state and local governments and nonprofits, it is unclear how much each birth averted cost overall.
} 
Dryfoos, Joy G. The United States National Family Planning Program, 1968-74. Studies in Family Planning. 1976; 7(3):80-92. [PubMed: 775689]

Dryfoos, Joy G. Family Planning Clinics-A Story of Growth and Conflict. Family Planning Perspectives. 1988; 20(6):282-87. [PubMed: 3068070]

Forrest, Jacqueline Darroch; Hermalin, Albert I.; Henshaw, Stanley K. The Impact of Family Planning Clinic Programs on Adolescent Pregnancy. Family Planning Perspectives. 1981; 13(3):109-16. [PubMed: 7250347]

Gillette, Michael L. Launching the War on Poverty: An Oral History. New York: Twayne Publishers; 1996.

Gould, Ketayun H. Family Planning and Abortion Policy in the United States. Social Science Review. 1979; 53(3):452-63.

Guldi, Melanie. Fertility Effects of Abortion and Birth Control Pill Access for Minors. Demography. 2008; 45(4):817-27. [PubMed: 19110899]

Haines, Michael R. Inter-university Consortium for Political and Social Research. Historical, Demographic, Economic, and Social Data: The United States, 1790-2000 [Computer file]. ICPSR02896-v2. Hamilton, NY: Colgate University; Ann Arbor, MI: Inter-university Consortium for Political and Social Research [producers]; Ann Arbor, MI: Inter-university Consortium for Political and Social Research [distributor]; 2005. 20042005-04-29)

Harkavy, Oscar; Jaffe, Frederick S.; Wishik, Samuel M. Family Planning and Public Policy: Who Is Misleading Whom? Science. 1969; 165(3891):367-73. [PubMed: 5789434]

Helmerhorst, Frans M.; Belfield, Toni; Kulier, Regina; Maitra, Nandita; O’Brien, Paul; Grimes, David A. The Cochrane Fertility Regulation Group: Synthesizing the Best Evidence about Family Planning. Contraception. 2006; 74(4):280-86. [PubMed: 16982225]

Hotz, V Joseph; Klerman, Jacob Alex; Willis, Robert J. The Economics of Fertility in Developed Countries. In: Rosenzweig, Mark R.; Stark, Oded, editors. Handbook of Population and Family Economics. Vol. 1A. Amsterdam: North-Holland; 1997. p. 275-347.

Hoynes, Hilary W.; Schanzenbach, Diane Whitmore. Consumption Responses to In-Kind Transfers: Evidence from the Introduction of the Food Stamp Program. American Economic Journal: Applied Economics. 2009; 1(4):109-39.

Jacobson, Louis S.; LaLonde, Robert J.; Sullivan, Daniel G. Earnings Losses of Displaced Workers. American Economic Review. 1993; 83(4):685-709.

Joshi, Shareen; Paul Schultz, T. Yale University Economic Growth Center Discussion Paper. 2007. Family Planning as an Investment in Development: Evaluation of a Program's Consequences in Matlab, Bangladesh; p. 951

Joyce, Theodore; Kaestner, Robert; Kwan, Florence. Is Medicaid Pronatalist? The Effect of Eligibility Expansions on Abortions and Births. Family Planning Perspectives. 1998; 30(3):108-13. [PubMed: 9635258]

Kearney, Melissa S.; Levine, Phillip B. Subsidized Contraception, Fertility, and Sexual Behavior. Review of Economics and Statistics. 2009; 91(1):137-51. [PubMed: 20130787]

Kirby, Douglas. No Easy Answers: Research Findings on Programs to Reduce Teen Pregnancy. Washington, DC: The National Campaign to Prevent Teen Pregnancy; 1997.

Levine, Phillip B.; Staiger, Douglas; Kane, Thomas J.; Zimmerman, David J. National Bureau of Economic Research Working Paper. 1996. Roe v. Wade and American Fertility; p. 5615

Levine, Phillip B.; Trainor, Amy B.; Zimmerman, David J. The Effect of Medicaid Abortion Funding Restrictions on Abortions, Pregnancies and Births. Journal of Health Economics. 1996; 15(5):55578. [PubMed: 10164043]

Levitan, Sar A. The Great Society's Poor Law: A New Approach to Poverty. Baltimore: Johns Hopkins University Press; 1969.

Ludwig, Jens; Miller, Douglas L. Does Head Start Improve Children's Life Chances? Evidence from a Regression Discontinuity Design. Quarterly Journal of Economics. 2007; 122(1):159-208.

Mellor, Jennifer M. The Effect of Family Planning Programs on the Fertility of Welfare Recipients: Evidence from Medicaid Claims. Journal of Human Resources. 1998; 33(4):866-95. 
Michael, Robert T.; Willis, Robert J. Contraception and Fertility: Household Production under Uncertainty. In: Terleckyj, Nestor E., editor. Household Production and Consumption. Cambridge, MA: National Bureau of Economic Research; 1976. p. 25-98.

Miller, Grant. Contraception as Development? New Evidence from Family Planning in Colombia. Economic Journal. 2010; 120(545):709-36.

Moore, Kristen A.; Caldwell, Steven B. The Effect of Government Policies on Out-of-Wedlock Sex and Pregnancy. Family Planning Perspectives. 1977; 9(4):164-69. [PubMed: 881010]

National Academy of Sciences. The Growth of World Population: Analysis of the Problems and Recommendations for Research and Training. Committee on Science and Public Policy Publication; Washington, DC. April; 1963.

National Center for Health Statistics (NCHS). "Natality Detail File, 1968-1988.” [UNITED STATES] [Computer file]. Hyattsville, MD: U.S. Dept. of Health and Human Services, National Center for Health Statistics [producer]; Ann Arbor, MI: Inter-university Consortium for Political and Social Research [distributor]; 2003. 1981

National Center for Health Statistics (NCHS). "Multiple Cause of Death Files, 1959-1988." [Computer file]. Ann Arbor, MI: Inter-university Consortium for Political and Social Research [distributor]); 2008.

National Fertility Study. [machine readable data file]. Survey conducted by Norman B. Ryder and Charles F. Westoff for the Office of Population Research; data file prepared by the Center for Demography and Ecology. University of Wisconsin; Madison: Princeton, NJ: Office of Population Research [producer]; Madison, WI: University of Wisconsin Data and Program Library Service [distributor]; 1965. 1965

National Fertility Study. Westoff for the Office of Population Research; data file prepared under the direction of Larry Bumpass. Center for Demography and Ecology, University of Wisconsin, Madison; Princeton, NJ: Office of Population Research [producer]; Madison, WI: University of Wisconsin Data and Program Library Service [distributor]; 1970. [machine readable data file]. Survey conducted by Norman B. Ryder and Charles F. 19701976

Office of Economic Opportunity (OEO). The Need for Subsidized Family Planning Services: United States, Each State and County, 1968. Washington, DC: Government Printing Office; 1969.

Office of Economic Opportunity (OEO). The Need for Subsidized Family Planning Services: United States, Each State and County, 1969. Washington, DC: Government Printing Office; 1971.

Office of Economic Opportunity (OEO). The Need for Subsidized Family Planning Services: United States, Each State and County, 1971. Washington, DC: Government Printing Office; 1974.

Office of Population Affairs (OPA). [accessed February 7, 2009] US Department of Health and Human Services. 2009. http://www.hhs.gov/opa/about/budget

Regional Economic Information System (REIS). [accessed February 2009] Bureau of Economic Analysis, US Department of Commerce. 1969-1989. http://www.ciesin.org/datasets/reis/reis-home.html

Rosenzweig, Mark R.; Wolpin, Kenneth I. Evaluating the Effects of Optimally Distributed Public Programs: Child Health and Family Planning Interventions. American Economic Review. 1986; 76(3):470-82.

Salehi-Isfahani, Djavad; Jalal Abbasi-Shavazi, M.; Hosseini-Chavoshi, Meimanat. Family Planning and Rural Fertility Decline in Iran: A Study in Program Evaluation. 2008.

Schultz, T Paul. Explanation of Birth Rate Changes over Space and Time: A Study of Taiwan. Journal of Political Economy. 1973; 81(2):S238-74.

Schultz, T Paul. Assessing Family Planning Cost-Effectiveness: Applicability of Individual DemandProgramme Supply Framework. In: Phillips, James F.; Ross, John A., editors. Family Planning Programmes and Fertility. New York: Oxford University Press; 1992. p. 78-105.

Schultz, T Paul. Population Policies, Fertility, Women's Human Capital, and Child Quality. In: Paul Schultz, T.; Strauss, John, editors. Handbook of Development Economics. Vol. 4. Amsterdam: Elsevier; 2008. p. 3249-304.

Surveillance Epidemiology and End Results (SEER) Program Populations. National Cancer Institute, DCCPS, Surveillance Research Program, Cancer Statistics Branch; 1969-1988. www.seer.cancer.gov/popdata 
Tone, Andrea. Devices and Desires: A History of Contraceptives in America. New York: Hill and Wang; 2001.

Trussell, James. Contraceptive Efficacy. In: Hatcher, Robert A.; Trussell, James; Nelson, Anita L.; Cates, Willard, Jr; Stewart, Felicia H.; Kowal, Deborah, editors. Contraceptive Technology. 18. New York: Ardent Media; 2004. p. 747-826.

Udry, J Richard; Bauman, Karl E.; Morris, Naomi M. The Effect of Subsidized Family Planning Services on Reproductive Behavior in the United States, 1969-1974. Demography. 1976; 13(4): 463-78. [PubMed: 992170]

United States Department of Health and Human Services, National Center for Health Statistics. "National Natality Followback Survey, 1964-1966." [Computer file]. ICPSR21961-v1. Hyattsville, MD: United States Department of Health and Human Services, National Center for Health Statistics [producer]; Ann Arbor, MI: Inter-university Consortium for Political and Social Research [distributor]; 2008-08-22

U. S. Department of Health, Education, and Welfare (DHEW), Center for Family Planning Program Development (Planned Parenthood-World Population). Report of the National Center for Family Planning Services, Health Services and Mental Health Administration. Rockville, MD: U.S. Government Printing Office; 1974. Family Planning, Contraception, and Voluntary Sterilization: An Analysis of Laws and Policies in the United States, each State and Jurisdiction (as of September 1971).

Weingarden CR. The Fertility of AFDC Women: An Econometric Analysis. Journal of Economics and Business. 1974; 26(3):159-66.

Wilmoth, John R.; Ball, Patrick. The Population Debate in American Popular Magazines, 1946-90. Population and Development Review. 1992; 18(4):631-68.

Wilmoth, John R.; Ball, Patrick. Arguments and Action in the Life of a Social Problem: A Case Study of 'Overpopulation,' 1946-1990. Social Problems. 1995; 42(3):318-43.

\section{Data Appendix}

\section{A. Description of County-Level Natality Data}

\section{Natality Data for 1959-1967}

The data for 1959-1967 were double-entered from published volumes of the Vital Statistics Division of the National Center for Health Statistics (NCHS, formerly the National Office of Vital Statistics). These records were compiled by Vital Statistics using microfilm copies of transcripts or state data files of all original birth certificates sent by states to the NCHS. All births are classified according to the place of residence of the mother. Data for the years 1959-1966 are based on a 50 percent sample consisting of only the even-numbered live birth records. The data for 1967 are based on a 20-50 percent sample (depending upon the state). The NCHS generated the published counts by multiplying the samples by 2 in the case of a 50 percent sample and 5 in the case of a 20 percent sample.

\section{Completeness of Birth Registration (1959-1967)}

The data do provide a representative sample of all registered births. Although there were state laws requiring that all births and deaths be registered, the degree of compliance and enforcement varied by state and over the course of the sample.

The NCHS conducted two tests of birth registration completeness. The first test was conducted based on records for infants born between December 1, 1939 and March 31, 1940, that were alive on April 1, 1940. The second test was conducted based on infants born between January 1, 1950 and March 31, 1950, and is fully described in chapter 6 of the 1950 Vital Statistics Volume. Both of these tests were implemented in a similar manner. During both testing periods census enumerators filled out infant cards for children born during the months of the test. State Vital Statistics offices then provided NCHS with copies of all infant 
birth and death records from the test period. These two sets of records were matched by NCHS. A follow-up mail survey was sent to the institutions where any unmatched births occurred as well as to the parents' places of residence. More records were matched after additional information was obtained from the follow-up mail survey. Any remaining records were checked against other sources of information from the states (e.g., adoption records). The completeness of birth registration in each area was then determined by comparing the number of matched records to the total number of infant cards and death records for the area.

The percent completeness was higher in 1950 than in 1940. In 1950, the NCHS estimated that 98.1 percent of all births in the nation were registered: 98.8 percent for whites and 94.1 percent for the nonwhite (US DHHS 1950, XXI). In both tests of birth registration completeness, births that occurred in hospitals had higher completion rates than births occurring outside hospitals. By 1960, NCHS estimated that birth registration was 98.9 percent complete (US DHHS 1965, 4-9). The counts of birth-related variables given by county were not adjusted for the completeness of registration.

\section{Data Limitations}

For all years before 1964, birth certificates for many intrastate nonresidents of Massachusetts were received from the place of occurrence of the birth as well as from the place of the mother's residence. This produced some duplication and the Technical Appendix from 1964 gives an estimate of a 4 percent overstatement of the number of births (US DHHS 1964, 4-10). Also in 1964, 1,800 birth records for Massachusetts were not received by the NCHS, and so live birth figures are understated (US DHHS 1969, 4-10). Therefore, the sample of consistently identified counties for 1946-1988 excludes all counties in Massachusetts.

\section{Natality Data for 1968-1988}

The data for 1968-1988 were taken from NCHS Natality Detail Files (ICPSR Study Numbers 3241, 3242, 3244, 3243, 3245, 3246, 3247, 3248, 3249, 3250, 3251, 3304, 3305, $3307,3327,3308,3309,3310,3311,3312$, and 6651). The files contain information entered from individual birth certificates during each calendar year. Data for the years 1968-1971 are based on a 50 percent sample. All births are classified according to the place of residence of the mother or according to the place of occurrence of the birth. Births to Americans outside of the United States are not recorded in these data, although births to foreigners in the United States are recorded and assigned to the county of occurrence. Race information was aggregated into county of residence categories to match the pre-1968 data.

\section{Natality Variable Definitions}

Most of the variables have been calculated based on the usual place of residence of the mother as reported on the birth certificate. Until 1964, births to nonresident aliens were classified with the place of residence being the exact place of occurrence of the birth within the county. From 1964 until the end of the sample, these births were allocated to the "Balance of County" of the county of occurrence rather than to the exact place of birth within the county (US DHHS 1964, 4-5).

\section{B. Description of County-Level Population Data, 1959-1988}

County-level population data for the number of women per county between the ages of 15 and 44 are taken from the census and from the Surveillance Epidemiology and End Result (SEER) published by the National Cancer Institute. County-level information from the 1940, 1950, and 1960 censuses were compiled by Michael Haines for the Inter-university Consortium for Political and Social Research (study 2896), and linear interpolation was used 
to generate population denominators between 1959 and 1969. The Surveillance Epidemiology and End Result's data cover the period 1969-1988 in single years, and dictionary files were adapted from those written by Jean Roth of the National Bureau of Economic Research (NBER, Retrieved on Sept 1, 2008 from http://www.nber.org/data/vital-statistics-mortality-data-mulitiple-cause-of-death.html). Several counties are missing population data in at least one year. Counties missing this data are listed below:

\begin{tabular}{ll}
\hline Arizona: & Yuma \\
Colorado: & Adams, Boulder, Jefferson, Weld \\
Florida: & Dade New Mexico: Los Alamos, Valencia \\
New York: & New York South Dakota: Washabaugh \\
Virginia: & $\begin{array}{l}\text { Alleghany, Arlington, Henry, James City, Rockingham, Spotsylvania, Stafford, York, Alexandria City, } \\
\text { Clifton Forge City, Covington City, Falls Church City, Fredericksburg City, Galax City, Harrisonburg }\end{array}$ \\
& City, Martinsville City, Norton City, Williamsburg City
\end{tabular}

\section{Anomalies in the Data Changes in County Boundaries}

Several counties combined or split during the sample period. I account for those boundary changes by aggregating the affected counties for the entire sample period. Only boundary changes that resulted in the creation or elimination of counties are reflected. I account for boundary revisions only if they resulted in a name or county federal information processing standard code change. These changes were verified by comparison with listed county changes from the census or against table footnotes from the Vital Statistics Volumes. The boundary changes are as follows:

South Boston City, Virginia was completely absorbed into Halifax County, Virginia in 1960.

Fairfax City, Virginia became independent of Fairfax County, Virginia in 1961.

Franklin City, Virginia became independent of Southampton, Virginia in 1961.

Menominee County, Wisconsin was formed from the Menominee Indian Reservation, Oconto and Shawano counties, Wisconsin in 1961.

Norfolk County, Virginia and South Norfolk City, Virginia combined to form Chesapeake City in 1963.

Princess Anne County, Virginia was completely absorbed into Virginia Beach City, Virginia in 1963.

Lexington City, Virginia became independent of Rockbridge County, Virginia in 1966.

Emporia City, Virginia became independent of Greenville County, Virginia in 1967.

Bedford City, Virginia became independent of Bedford County, Virginia in 1968.

Roanoke City, Virginia and Salem City, Virginia became independent of Roanoke County, Virginia in 1968.

Ormsby County, Nevada merged with Carson City, Nevada in 1969. 
Nansemond County, Virginia was incorporated into Suffolk City, Virginia in 1972.

Manassas City, Virginia and Manassas Park City, Virginia became independent of Prince William County, Virginia in 1975.

\section{Natality Data Anomalies for 1959-1967}

1961: Alabama nonwhite and white totals for Dallas County did not sum to published total for number of live births by place of occurrence.

1962: Ohio nonwhite total and white total did not sum to published total for number of live births by place of occurrence; Ohio nonwhite and white totals for Cuyahoga, Hamilton, Montgomery, Stark, and Summit Counties did not sum to published total for number of live births by place of occurrence.

1963: Wisconsin nonwhite total and white total did not sum to published total for number of live births by place of occurrence.

1964: Indiana totals for DeKalb and Lagrange counties were illegible for number of live births by place of occurrence.

1965: California total for Lake County was illegible for number of births by attendant (other) by place of residence; North Carolina Total for Mitchell County was illegible for number of births by attendant (other) by place of residence.

\section{Bibliographic Information for Data Appendix}

National Center for Health Statistics. 2000. Data File Documentations, Compressed Mortality File, 1968-1988 (machine readable data file and documentation, CD-ROM Series 20, No. 2A), National Center for Health Statistics, Hyattsville, Maryland.

National Center for Health Statistics. 2000. Data File Documentations, Multiple Cause of Death Files, 1959-1988 (machine readable data file and documentation, CD-ROM Series 20), National Center for Health Statistics, Hyattsville, Maryland.

Roth, Jean. December 1, 2000. Mortality Data-Vital Statistics NCHS's Multiple Cause of Death Data, 1959-2005. National Bureau of Economic Research. Retrieved September 1, 2008, from http://www.nber.org/data/vital-statistics-mortality-data-mulitiple-cause-of-death.html.

Surveillance Epidemiology and End Result, National Cancer Institute. 2001. Data files, Single Year of Age County Population Estimates, 1969-1988, National Cancer Institute, Bethesda, Maryland. Retrieved October 1, 2008 from http://seer.cancer.gov/popdata/download.html\#single.

US Department of Health, Education, and Welfare; Public Health Service. 1959. Vital Statistics of the United States, Volume I. Washington, DC: US Government Printing Office.

US Department of Health, Education, and Welfare; Public Health Service. 1960. Vital Statistics of the United States, Volume I. Washington, DC: US Government Printing Office.

US Department of Health, Education, and Welfare; Public Health Service. 1961. Vital Statistics of the United States, Volume I. Washington, DC: US Government Printing Office. 
US Department of Health, Education, and Welfare; Public Health Service. 1962. Vital Statistics of the United States, Volume I. Washington, DC: US Government Printing Office.

US Department of Health, Education, and Welfare; Public Health Service. 1963. Vital Statistics of the United States, Volume I. Washington, DC: US Government Printing Office.

US Department of Health, Education, and Welfare; Public Health Service. 1964. Vital Statistics of the United States, Volume I. Washington, DC: US Government Printing Office.

US Department of Health, Education, and Welfare; Public Health Service. 1965. Vital Statistics of the United States, Volume I. Washington, DC: US Government Printing Office.

US Department of Health, Education, and Welfare; Public Health Service. 1966. Vital Statistics of the United States, Volume I. Washington, DC: US Government Printing Office.

US Department of Health, Education, and Welfare; Public Health Service. 1967. Vital Statistics of the United States, Volume I. Washington, DC: US Government Printing Office.

US Department of Health, Education, and Welfare; Public Health Service. 1968. Vital Statistics of the United States, Volume I. Washington, DC: US Government Printing Office.

US Dept. of Health and Human Services, National Center for Health Statistics. NATALITY DETAIL FILE, 1968: [UNITED STATES] [Computer file]. Hyattsville, MD: US Dept. of Health and Human Services, National Center for Health Statistics [producer], 1969. Ann Arbor, MI: Inter-university Consortium for Political and Social Research [distributor], 2002. doi:10.3886/ICPSR03241.

US Dept. of Health and Human Services, National Center for Health Statistics. NATALITY DETAIL FILE, 1969: [UNITED STATES] [Computer file]. Hyattsville, MD: US Dept. of Health and Human Services, National Center for Health Statistics [producer], 1970. Ann Arbor, MI: Inter-university Consortium for Political and Social Research [distributor], 2002. doi:10.3886/ICPSR03242.

US Dept. of Health and Human Services, National Center for Health Statistics. NATALITY DETAIL FILE, 1970: [UNITED STATES] [Computer file]. Hyattsville, MD: US Dept. of Health and Human Services, National Center for Health Statistics [producer], 1971. Ann Arbor, MI: Inter-university Consortium for Political and Social Research [distributor], 2002. doi:10.3886/ICPSR03244.

US Dept. of Health and Human Services, National Center for Health Statistics. NATALITY DETAIL FILE, 1971: [UNITED STATES] [Computer file]. Hyattsville, MD: US Dept. of Health and Human Services, National Center for Health Statistics [producer], 1972. Ann Arbor, MI: Inter-university Consortium for Political and Social Research [distributor], 2002. doi:10.3886/ICPSR03243.

US Dept. of Health and Human Services, National Center for Health Statistics. NATALITY DETAIL FILE, 1972: [UNITED STATES] [Computer file]. Hyattsville, MD: US Dept. of Health and Human Services, National Center for Health Statistics [producer], 1973. Ann Arbor, MI: Inter-university Consortium for Political and Social Research [distributor], 2002. doi:10.3886/ICPSR03245.

US Dept. of Health and Human Services, National Center for Health Statistics. NATALITY DETAIL FILE, 1973: [UNITED STATES] [Computer file]. Hyattsville, MD: US Dept. of Health and Human Services, National Center for Health Statistics [producer], 
1974. Ann Arbor, MI: Inter-university Consortium for Political and Social Research [distributor], 2002. doi:10.3886/ICPSR03246.

US Dept. of Health and Human Services, National Center for Health Statistics. NATALITY DETAIL FILE, 1974: [UNITED STATES] [Computer file]. Hyattsville, MD: US Dept. of Health and Human Services, National Center for Health Statistics [producer], 1975. Ann Arbor, MI: Inter-university Consortium for Political and Social Research [distributor], 2002. doi:10.3886/ICPSR03247.

US Dept. of Health and Human Services, National Center for Health Statistics. NATALITY DETAIL FILE, 1975: [UNITED STATES] [Computer file]. Hyattsville, MD: US Dept. of Health and Human Services, National Center for Health Statistics [producer], 1976. Ann Arbor, MI: Inter-university Consortium for Political and Social Research [distributor], 2002. doi:10.3886/ICPSR03248.

US Dept. of Health and Human Services, National Center for Health Statistics. NATALITY DETAIL FILE, 1976: [UNITED STATES] [Computer file]. Hyattsville, MD: US Dept. of Health and Human Services, National Center for Health Statistics [producer], 1977. Ann Arbor, MI: Inter-university Consortium for Political and Social Research [distributor], 2002. doi:10.3886/ICPSR03249.

US Dept. of Health and Human Services, National Center for Health Statistics. NATALITY DETAIL FILE, 1977: [UNITED STATES] [Computer file]. Hyattsville, MD: US Dept. of Health and Human Services, National Center for Health Statistics [producer], 1978. Ann Arbor, MI: Inter-university Consortium for Political and Social Research [distributor], 2002. doi:10.3886/ICPSR03250.

US Dept. of Health and Human Services, National Center for Health Statistics. NATALITY DETAIL FILE, 1978: [UNITED STATES] [Computer file]. Hyattsville, MD: US Dept. of Health and Human Services, National Center for Health Statistics [producer], 1979. Ann Arbor, MI: Inter-university Consortium for Political and Social Research [distributor], 2002. doi:10.3886/ICPSR03251.

US Dept. of Health and Human Services, National Center for Health Statistics. NATALITY DETAIL FILE, 1979: [UNITED STATES] [Computer file]. Hyattsville, MD: US Dept. of Health and Human Services, National Center for Health Statistics [producer], 1980. Ann Arbor, MI: Inter-university Consortium for Political and Social Research [distributor], 2003. doi:10.3886/ICPSR03304.

US Dept. of Health and Human Services, National Center for Health Statistics. NATALITY DETAIL FILE, 1980: [UNITED STATES] [Computer file]. Hyattsville, MD: US Dept. of Health and Human Services, National Center for Health Statistics [producer], 1981. Ann Arbor, MI: Inter-university Consortium for Political and Social Research [distributor], 2003. doi:10.3886/ICPSR03305.

US Dept. of Health and Human Services, National Center for Health Statistics. NATALITY DETAIL FILE, 1981: [UNITED STATES] [Computer file]. ICPSR version. Hyattsville, MD: US Dept. of Health and Human Services, National Center for Health Statistics [producer], 1983. Ann Arbor, MI: Inter-university Consortium for Political and Social Research [distributor], 2004. doi:10.3886/ICPSR03327.

US Dept. of Health and Human Services, National Center for Health Statistics. NATALITY DETAIL FILE, 1982: [UNITED STATES] [Computer file]. Hyattsville, MD: US Dept. of Health and Human Services, National Center for Health Statistics [producer], 
1984. Ann Arbor, MI: Inter-university Consortium for Political and Social Research [distributor], 2001. doi:10.3886/ICPSR03307.

US Dept. of Health and Human Services, National Center for Health Statistics. NATALITY DETAIL FILE, 1983: [UNITED STATES] [Computer file]. Hyattsville, MD: US Dept. of Health and Human Services, National Center for Health Statistics [producer], 1985. Ann Arbor, MI: Inter-university Consortium for Political and Social Research [distributor], 2001. doi:10.3886/ICPSR03308.

US Dept. of Health and Human Services, National Center for Health Statistics. NATALITY DETAIL FILE, 1984: [UNITED STATES] [Computer file]. Hyattsville, MD: US Dept. of Health and Human Services, National Center for Health Statistics [producer], 1986. Ann Arbor, MI: Inter-university Consortium for Political and Social Research [distributor], 2001. doi:10.3886/ICPSR03309.

US Dept. of Health and Human Services, National Center for Health Statistics. NATALITY DETAIL FILE, 1985: [UNITED STATES] [Computer file]. Hyattsville, MD: US Dept. of Health and Human Services, National Center for Health Statistics [producer], 1987. Ann Arbor, MI: Inter-university Consortium for Political and Social Research [distributor], 2001. doi:10.3886/ICPSR03310.

US Dept. of Health and Human Services, National Center for Health Statistics. NATALITY DETAIL FILE, 1986: [UNITED STATES] [Computer file]. Hyattsville, MD: US Dept. of Health and Human Services, National Center for Health Statistics [producer], 1988. Ann Arbor, MI: Inter-university Consortium for Political and Social Research [distributor], 2001. doi:10.3886/ICPSR03311.

US Dept. of Health and Human Services, National Center for Health Statistics. NATALITY DETAIL FILE, 1987: [UNITED STATES] [Computer file]. Hyattsville, MD: US Dept. of Health and Human Services, National Center for Health Statistics [producer], 1989. Ann Arbor, MI: Inter-university Consortium for Political and Social Research [distributor], 2001. doi:10.3886/ICPSR03312.

US Dept. of Health and Human Services, National Center for Health Statistics. NATALITY DETAIL FILE, 1988 [UNITED STATES] [Computer file]. Hyattsville, MD: US Dept. of Health and Human Services, National Center for Health Statistics [producer], 1990. Ann Arbor, MI: Inter-university Consortium for Political and Social Research [distributor], 1996. doi:10.3886/ICPSR06651. 


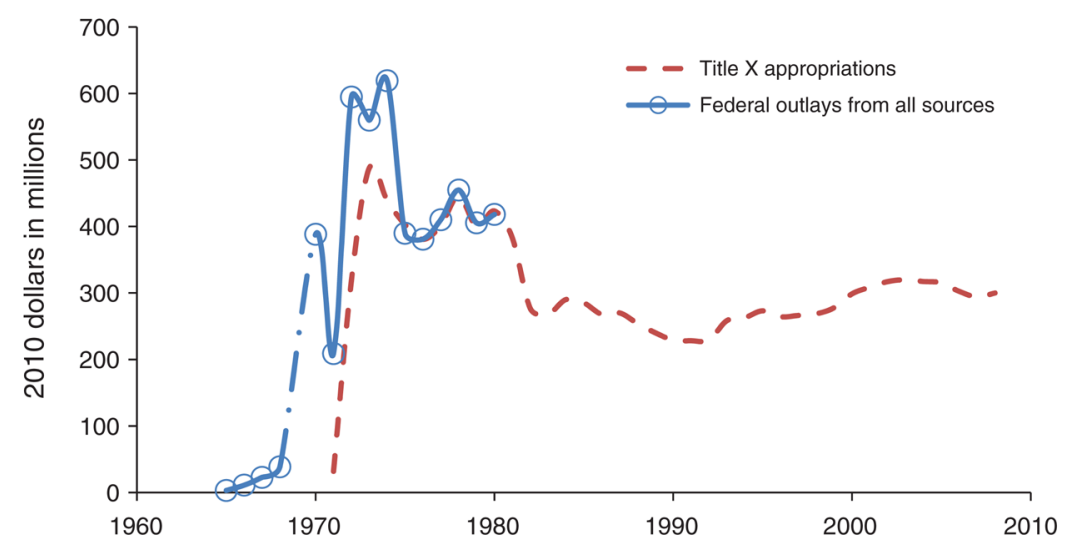

Figure 1.

Federal Spending on Family Planning, 1965-2008

Notes: No information is available for 1969, so a dashed line connects the 1968 and 1970 points. Title X appropriations differ from the inflation adjusted Table 14 in Alan Guttmacher Institute (AGI) (2000, 47), because I use the CPI-U and AGI (2000) uses the CPI for medical care.

Source: "Title X Appropriations" are taken from the Office of Population Affairs (2009). "Federal Outlays from All Sources" are computed by the author using the National Archives Community Action Program Data (NACAP) and the National Archives Federal Outlays Data (NAFO). 


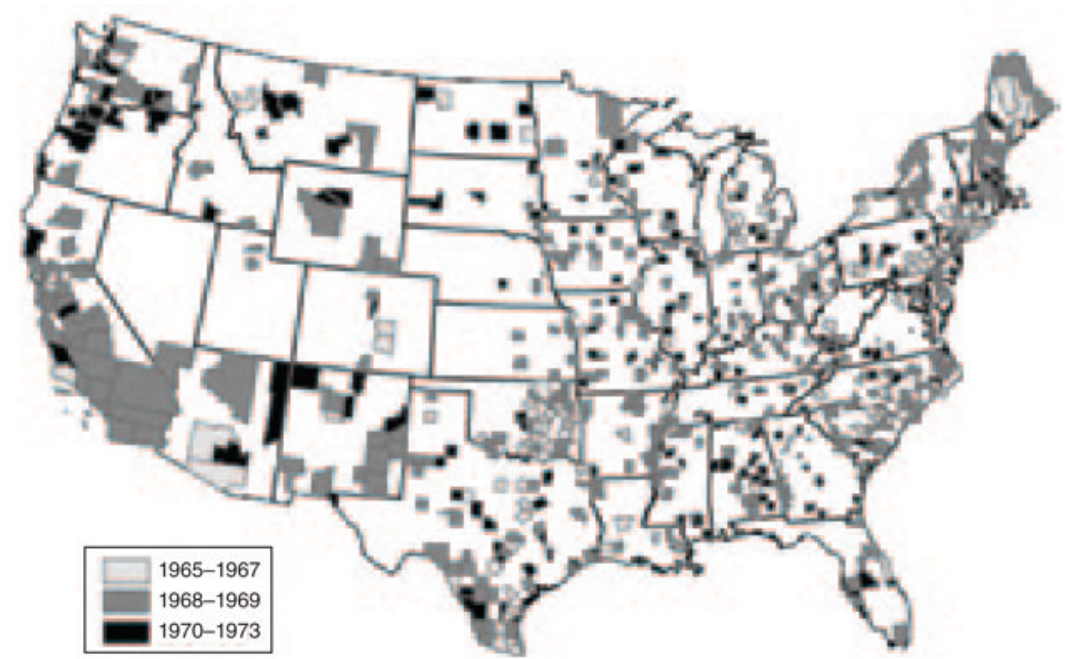

Figure 2.

The Establishment of Federal Family Planning Programs by Period, 1965-1973

Notes: Shading indicates the year the first federal family planning program was established in each county. Counties not receiving a family planning programs grant between 1965 and 1973, including a handful of communities that received funding but with an unknown starting date, are not shaded.

Source: NACAP, NAFO, and OEO $(1969,1971,1974)$. 
Panel A. Establishment date and 1964 General Fertility Rate (GFR)

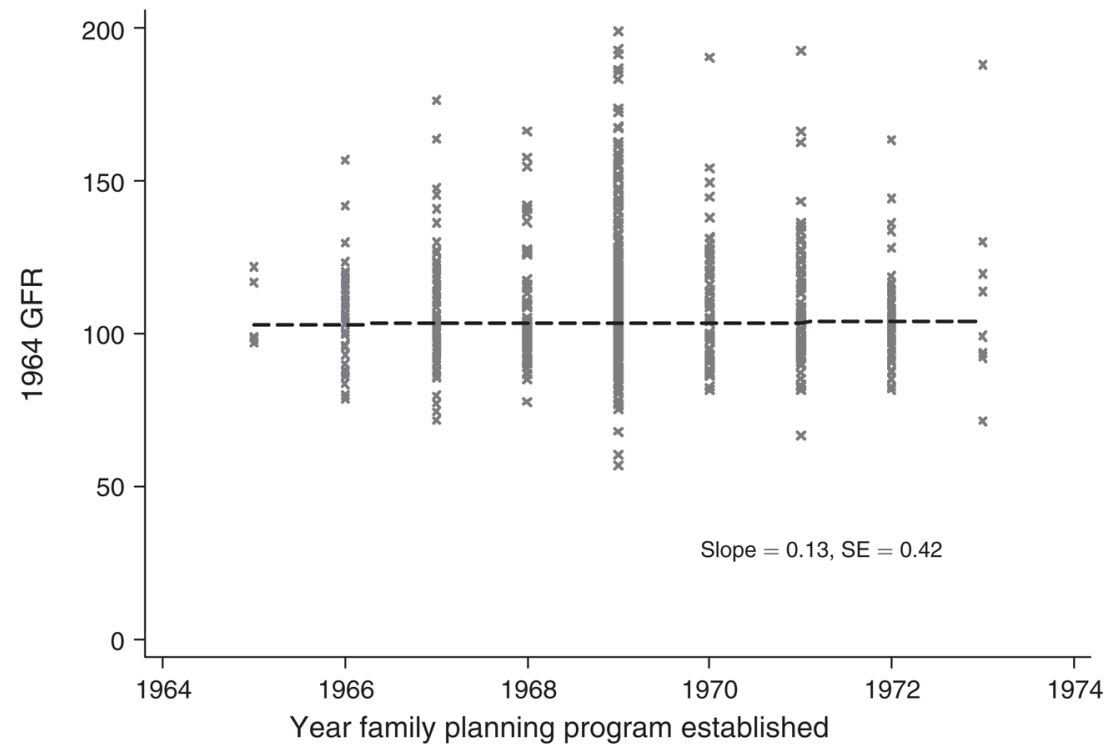

Panel B. Establishment date and 1960-1964 change in the GFR

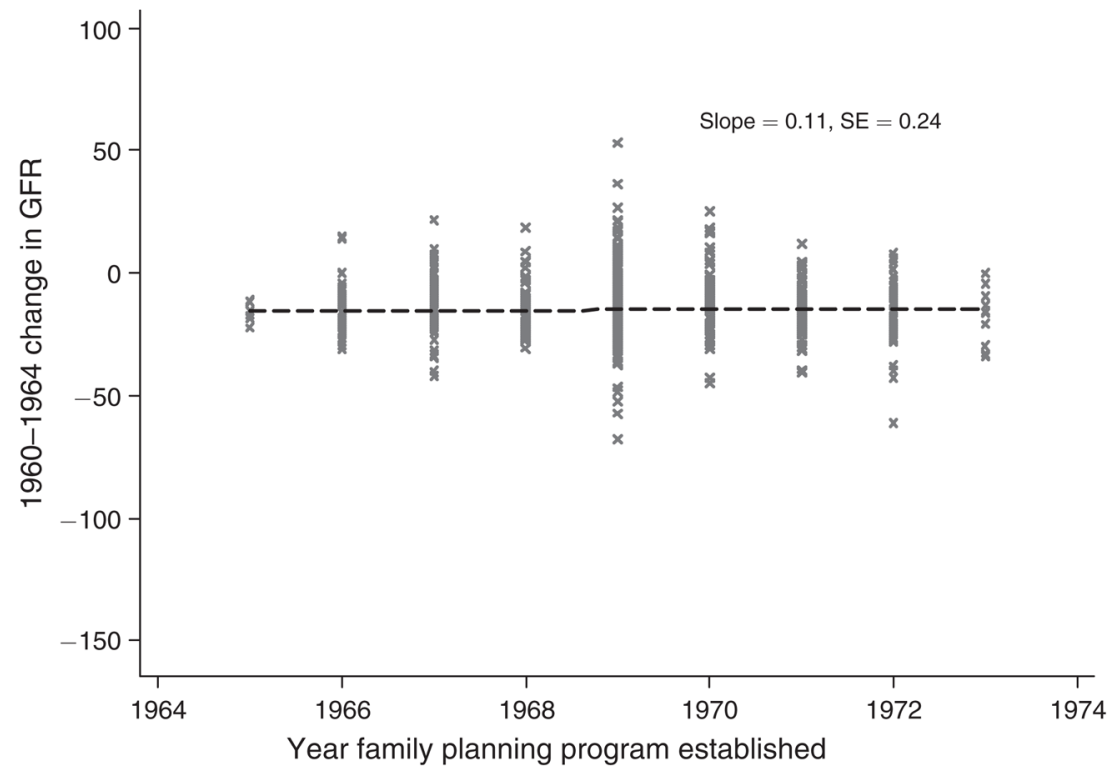

Figure 3.

Fertility Rates and the Roll-Out of Federal Family Planning Programs

Notes: The $X$-axis plots when the first federal family planning program was established in the county. The $y$-axis in panel A plots the 1964 GFR. The $y$-axis in panel B plots the change in the GFR from 1960 to 1964. The dashed lines indicate the estimated relationship between the $x$ and $y$ variables using linear regression. The estimated slope and standard error for each relationship are indicated.

Source: Family planning data: NACAP, NAFO, and OEO (1969, 1971, 1974). GFR: Handentered 1959-1967 county Vital Statistics and 1968-1988 Natality Detail Microdata Files (NCHS 2003). Denominators were constructed for 1959-1968 by linearly interpolating 
information between the 1950, 1960, and 1970 censuses; denominators for the 1969-1988 period use the Surveillance Epidemiology and End Results (SEER) data. 
Panel A. Changes in the General Fertility Rate (GFR), 1946-1988

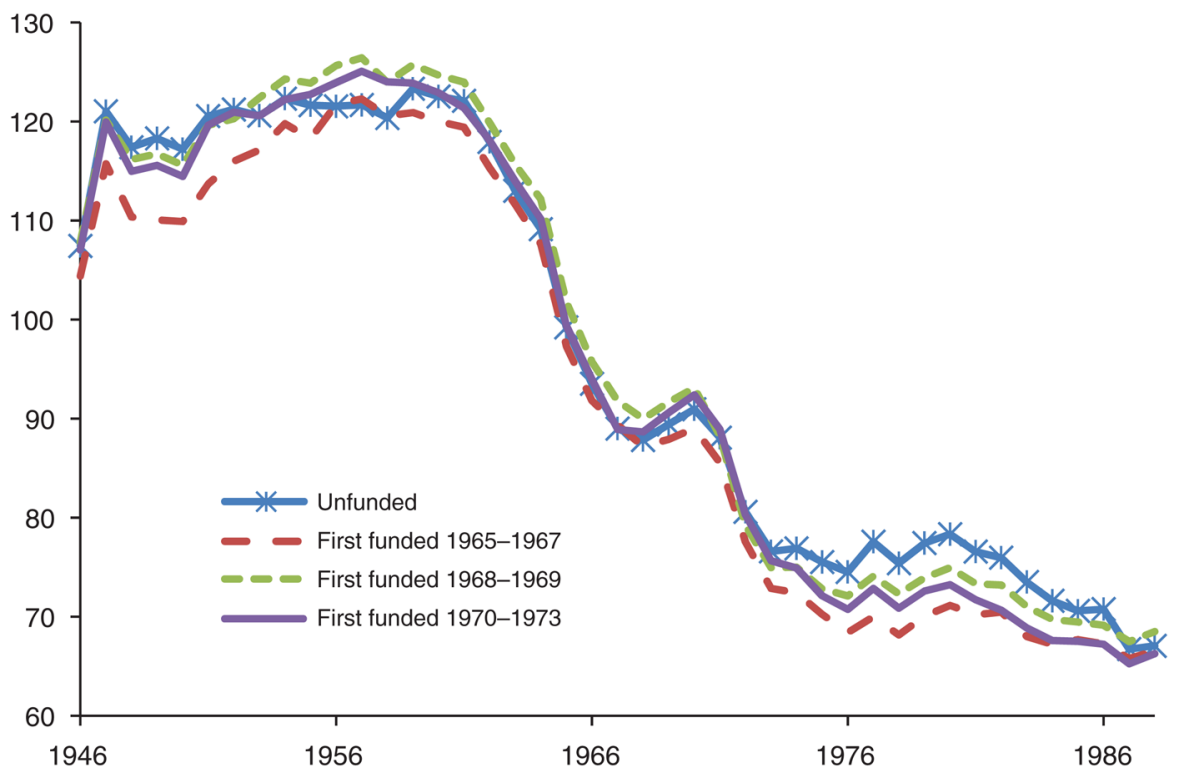

Panel B. Difference in GFR in funded counties and in unfunded counties by date of program establishment

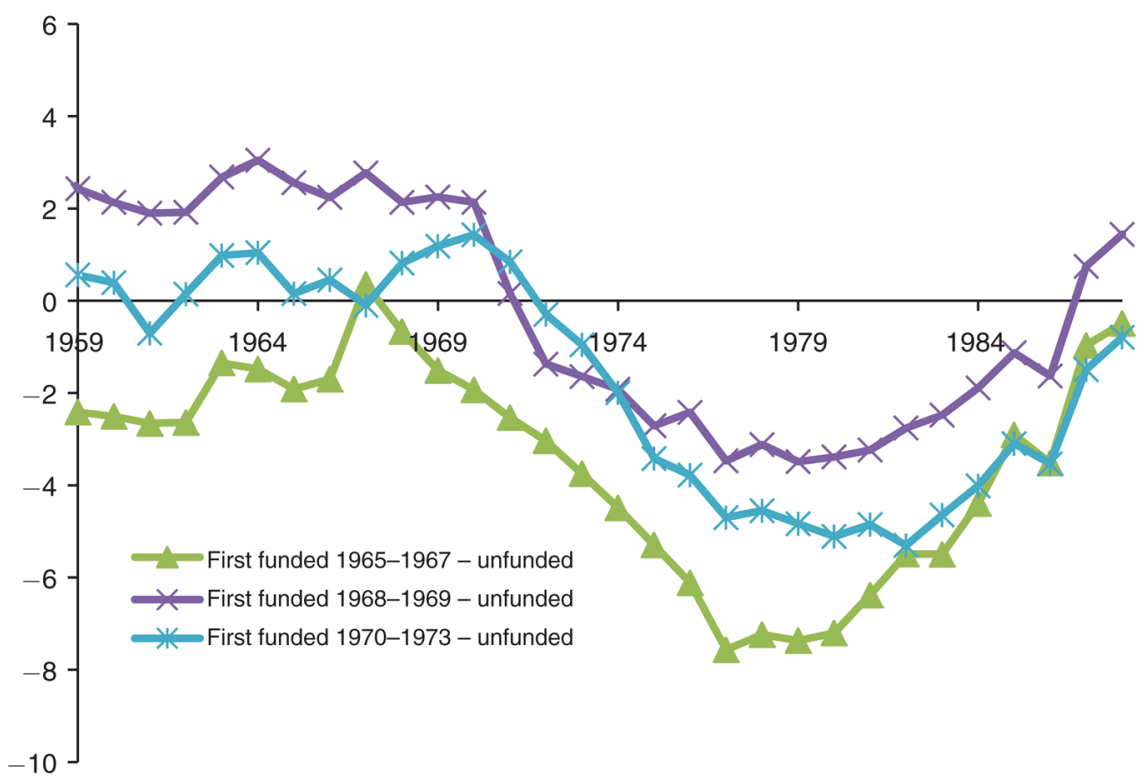

Figure 4.

Descriptive Evidence of the Effects of Family Planning on Fertility Rates

Notes: Panel A plots the evolution of the general fertility rate. Panel B plots the annual difference in the GFR between funded and unfunded counties by date range of program establishment. All estimates are unweighted.

Source: See Figure 3. 
Panel A. Family planning

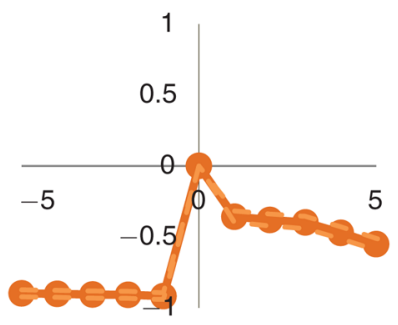

Panel D. Jobs programs

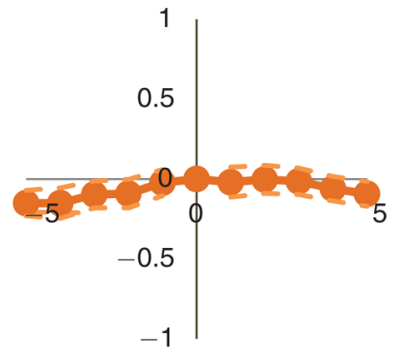

Panel B. Community health centers

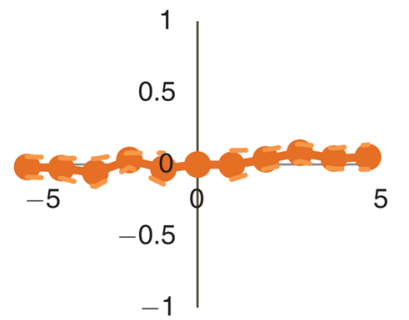

Panel E. Legal services

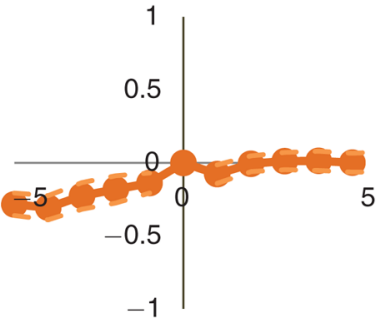

Panel G. Maternity and child health

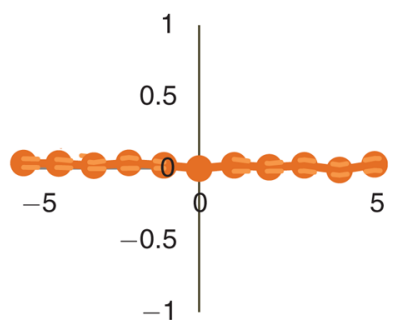

Panel C. Head Start

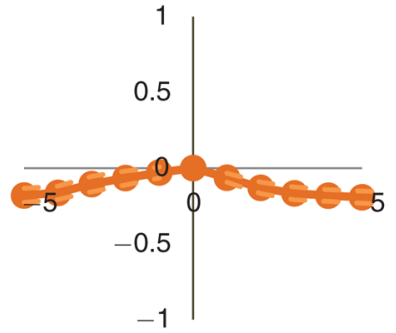

Panel F. Maternal and infant care

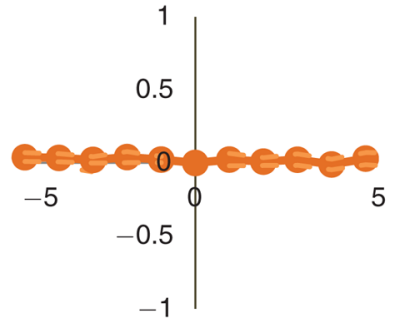

Figure 5.

The Relationship of the Roll-Out of Family Planning Programs with Other Federal Grants

Notes: Each panel plots weighted least squares estimates of $\pi$ and $\tau$ from equation (1) including fixed effects but excluding $X$ s (equivalent to model 2). The weights are the 1970 population of women ages 15-44. The dependent variable is equal to 1 if the county received any federal grant for the indicated program. Heteroskedasticity-robust standard errors clustered by county are used to construct point-wise, 95-percent confidence intervals, which are presented in dashed lines in each panel.

Source: NACAP and NAFO. 
Panel A. General fertility rate (weighted)

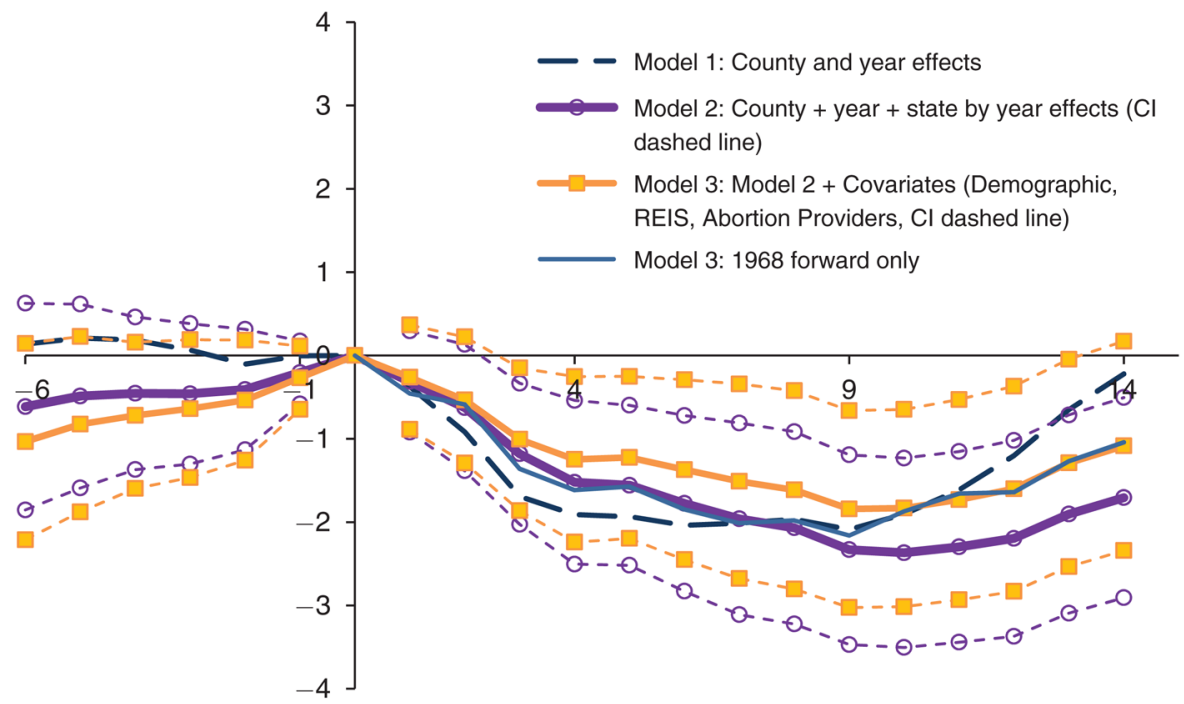

Panel B. General fertility rate (unweighted)

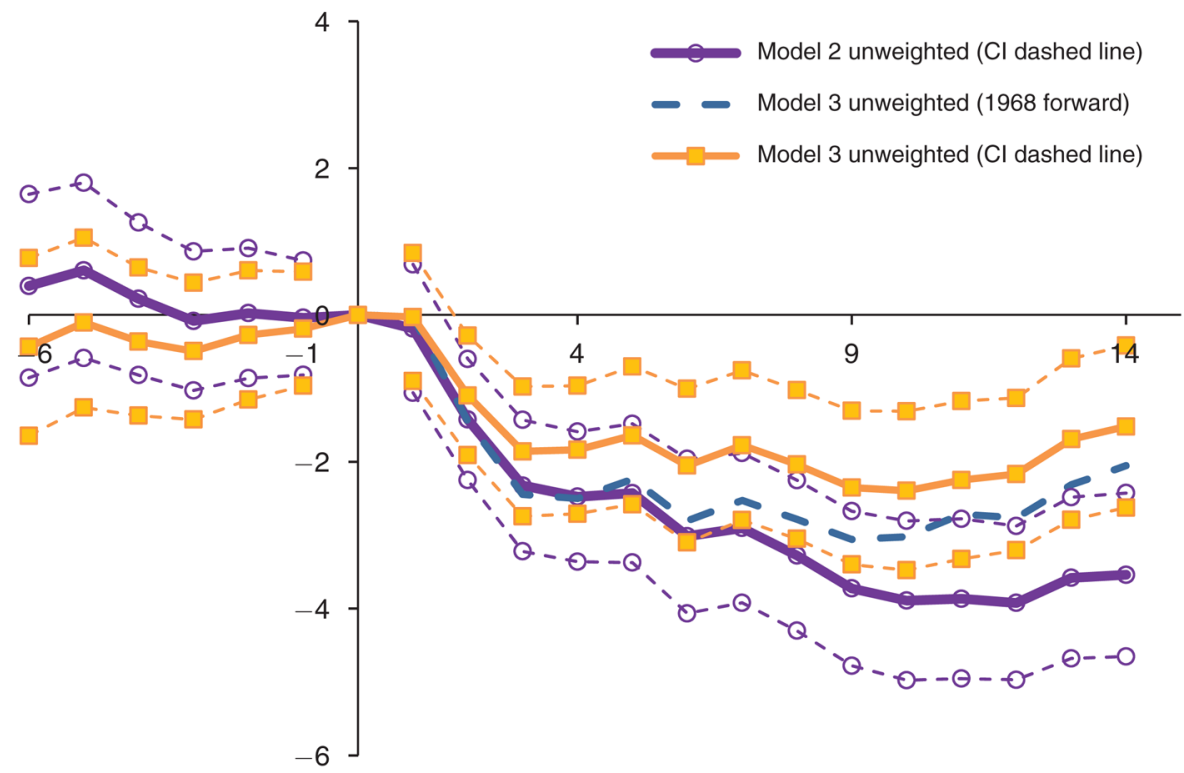

Figure 6.

The Effects of Federal Family Planning Programs on Fertility Rates

Notes: Panels plot either weighted or unweighted estimates of $\pi$ and $\tau$ from equation (1). Weights are the county population of women ages 15-44 in 1970. Heteroskedasticity-robust standard errors clustered by county construct 95 percent, point-wise confidence intervals (dashed lines).

Source: See Figure 3. 
Panel A. Birth rate by age group, 1968-1988
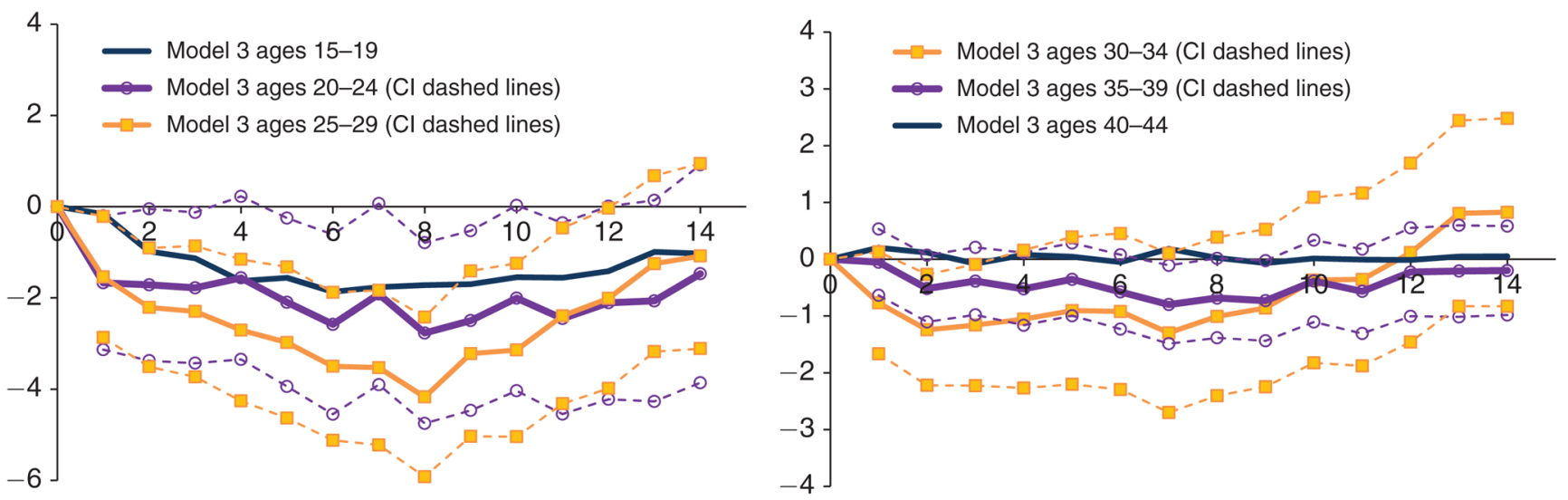

Panel B. Birth rate by parity, 1968-1988
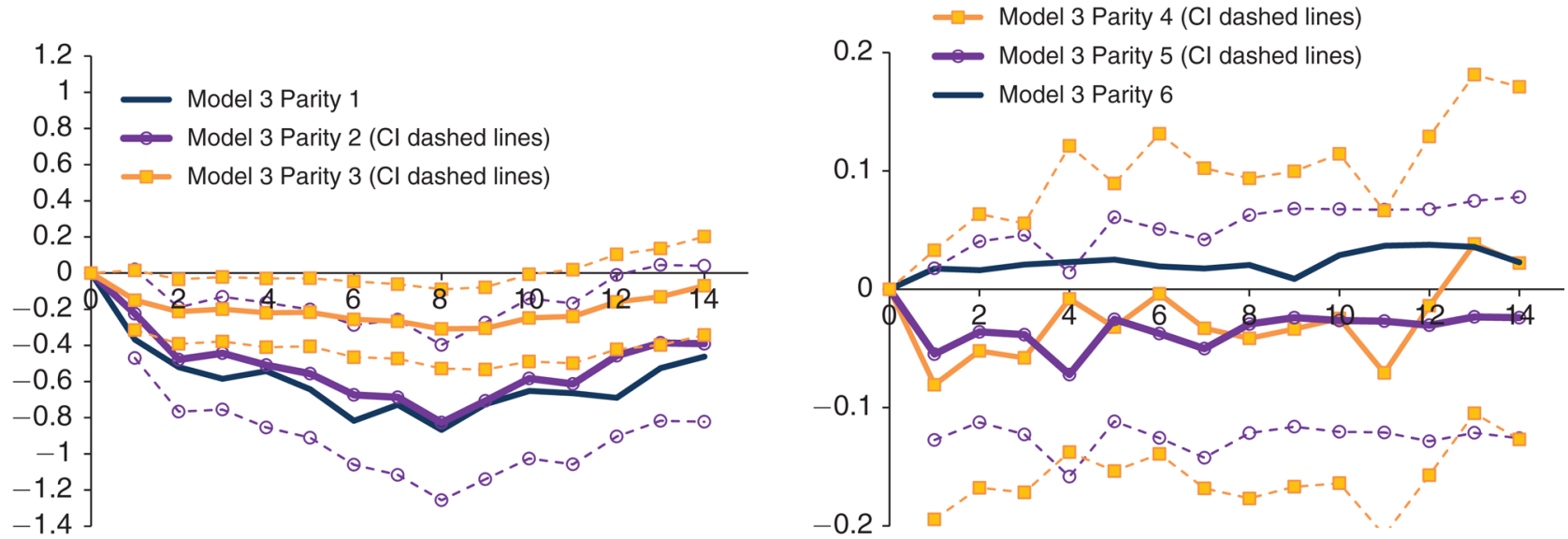

Figure 7.

The Effects of Federal Family Planning Programs on Fertility Rates, by Age and Parity Note: Panels present weighted, least squares estimates of $\tau$ from equation (1) for the indicated group for the 1968- 1988 data.

Source: Outcome data taken from 1968-1988 Natality Files (NCHS 2003). Denominators were constructed for 1959-1968 by linearly interpolating information between the 1950, 1960, and 1970 censuses; denominators for the 1969-1988 period use the Surveillance Epidemiology and End Results (SEER) data. Information on family planning programs drawn from NACAP, NAFO, and OEO $(1969,1971,1974)$ as described in text and footnote 8. 


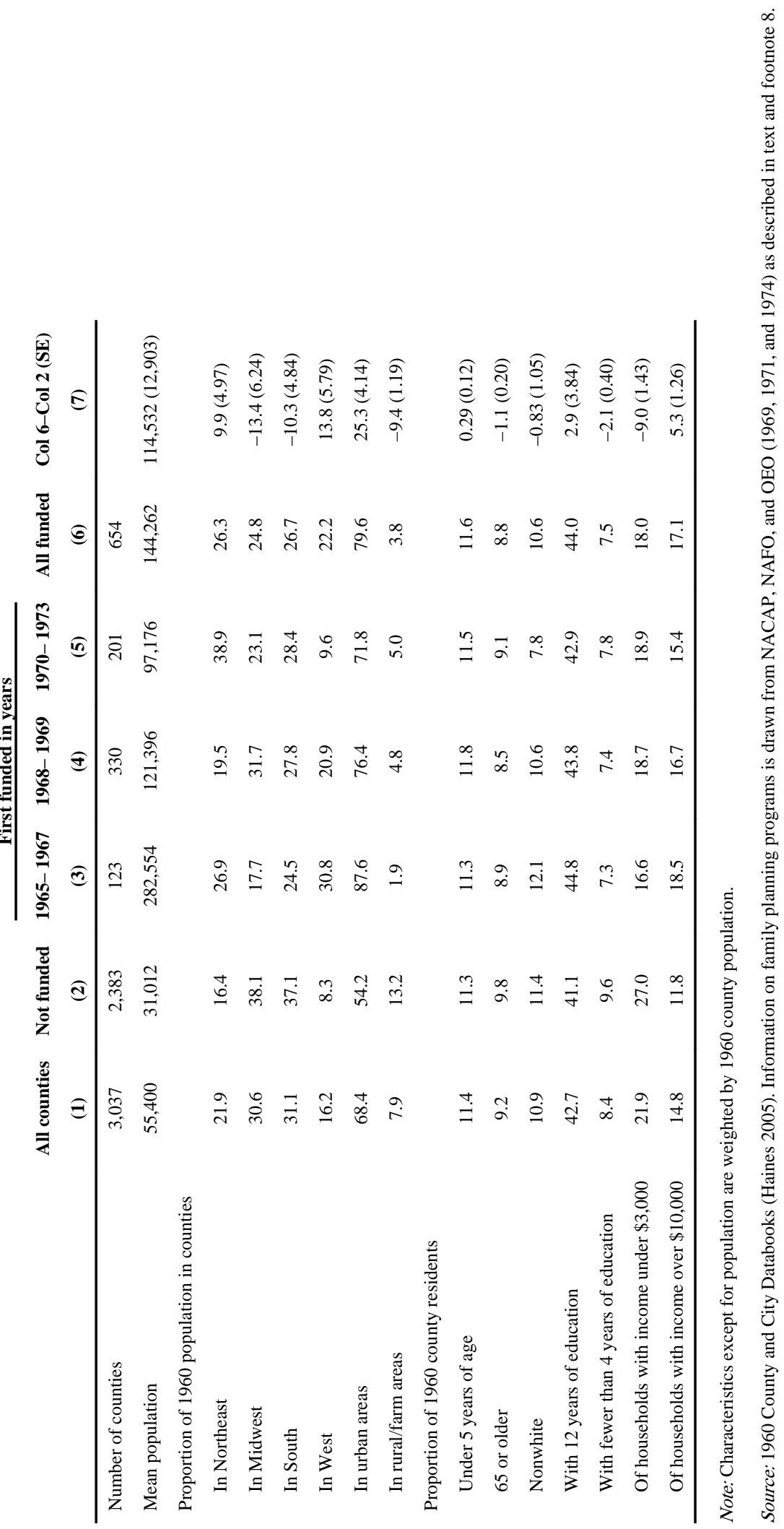




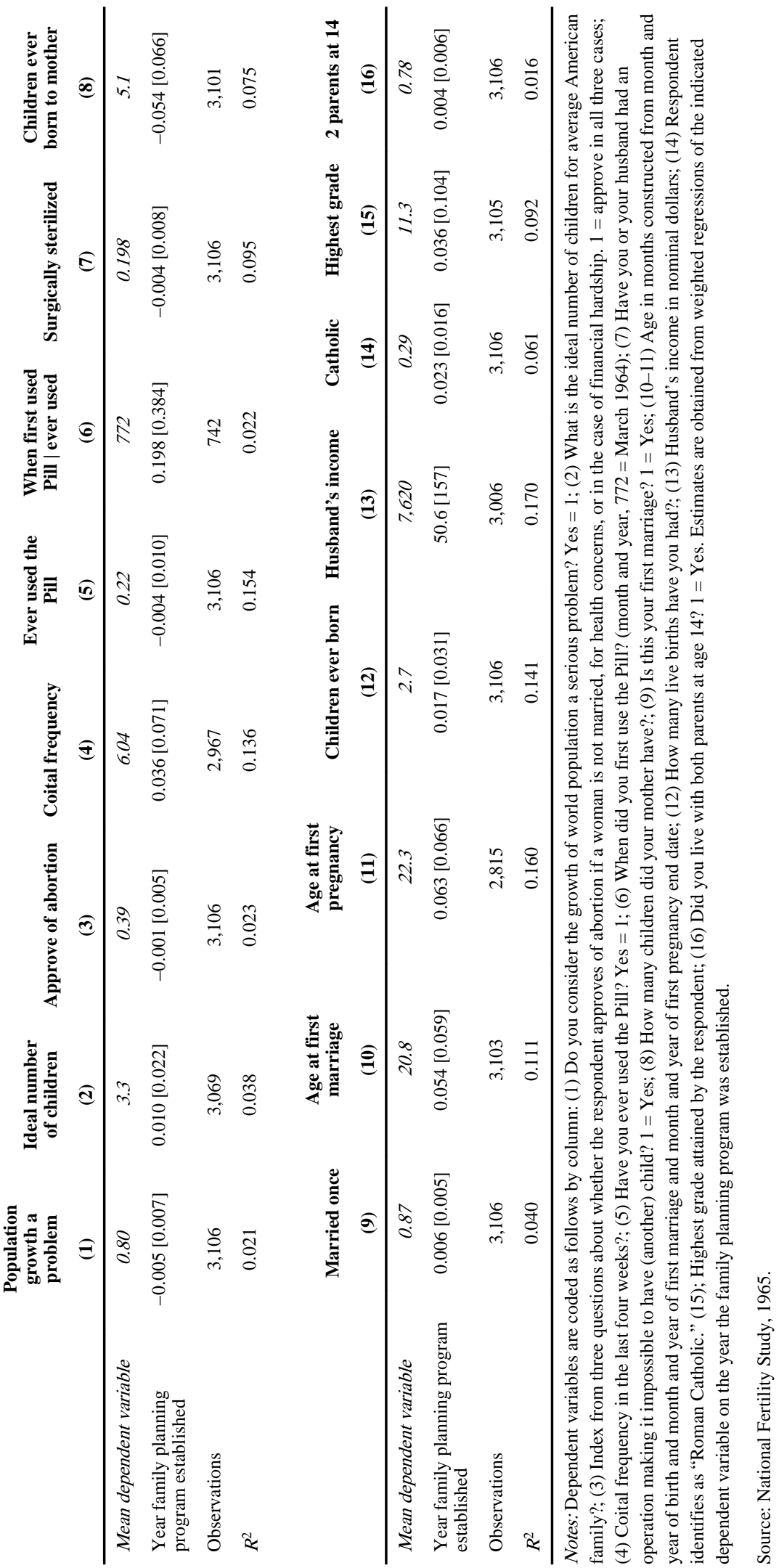




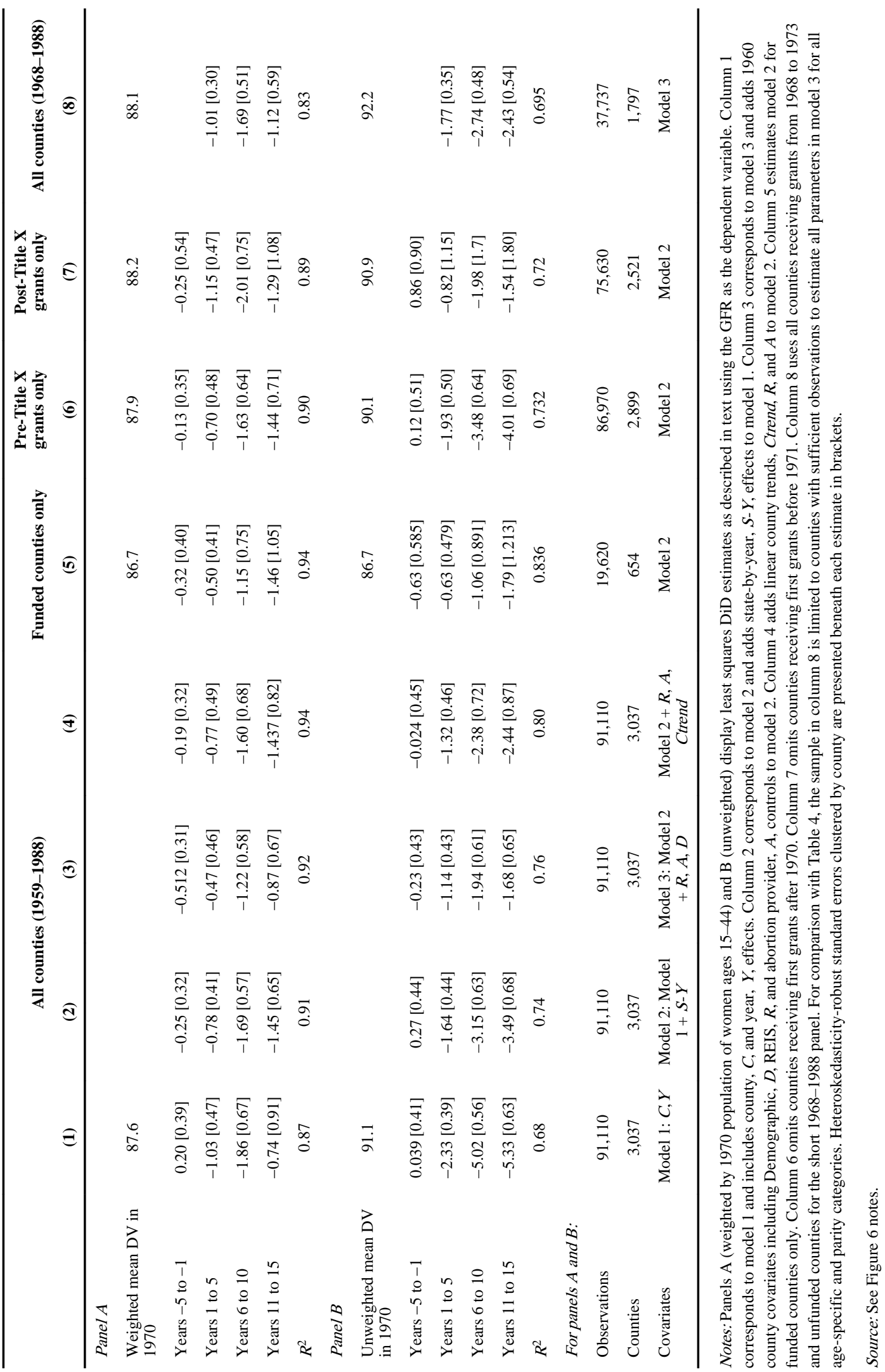


. 